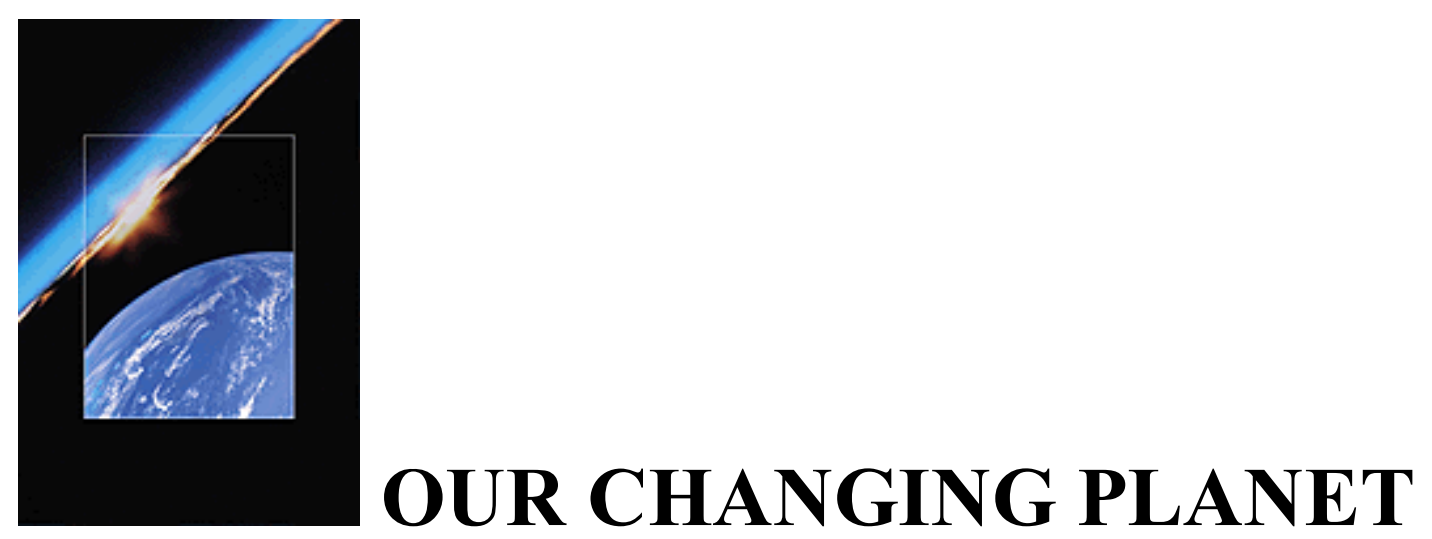

Above image (C) 1990 Lockheed Corporation and Smithsonian Institution

\title{
The FY 1995 U.S. Global Change Research Program
}

\section{Table of Contents}

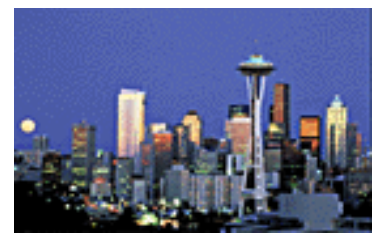

\section{INTRODUCTION}

The U.S. GLOBAL CHANGE RESEARCH PROGRAM (USGCRP) supports activities that provide information and policy-relevant understanding about the coupling of human activities and the environment across a broad range of issues, perspectives, and interactions.

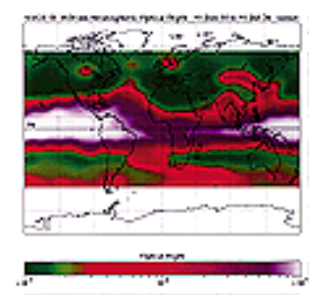

\section{ADDRESSING CRITICAL GLOBAL CHANGE ISSUES THROUGH A RESEARCH FRAMEWORK}

Global change research focuses on providing scientific insight into critical global change issues and policy choices facing the nation and the world community. Global change research to address these issues is organized into a flexible multidisciplinary framework for coordinating science activities. 


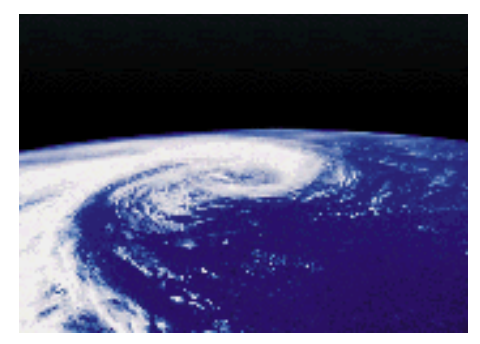

\section{THE FY 1995 U.S. GLOBAL CHANGE RESEARCH PROGRAM}

Each global change issue is addressed through a process which strives to document, understand, predict, and assess the science in a way that yields results that are relevant to the needs of decision makers.

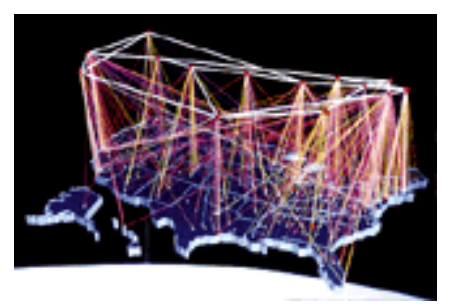

\section{LINKING TO THE INTERNATIONAL COMMUNITY}

The USGCRP is founded on the premise that international cooperation and coordination is fundamental to addressing global environmental issues. USGCRP programs significantly contribute to worldwide global change research efforts.

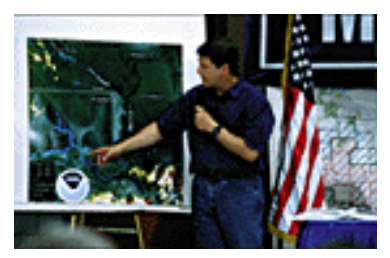

\section{GLOBAL CHANGE EDUCATION AND PUBLIC AWARENESS}

"The ultimate source of the strength of science will not be found in its impressive products or in its powerful instruments. It will be found in the minds of scientists, and in the discourse which scientists have developed in order to describe what they know..."

Above image (C) 1993, Paul Grabhorn

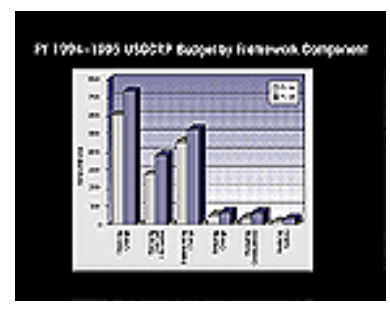

\section{APPENDICES}

\section{A: FY 1995 USGCRP Budget}



B: Agency Program Listings
C: List of Acronyms
D: Subcommittee on Global Change Research
E. USGCRP Management

Printed versions of Our Changing Planet: The FY 1995 U.S. Global Change Research Program are no longer available. Printed issues of later editions of Our Changing Planet are available from:

U.S. Global Change Research Information Office

Suite 250

1717 Pennsylvania Ave, NW

Washington, DC 20006.

Tel: +1 2022236262

Fax: +1 2022233065

Email: information@gcrio.org

Document Request Form 


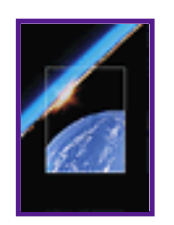

\section{Our Changing Planet FY 1995}

\section{INTRODUCTION}

President Clinton's Earth Day announcement on April 21, 1993 stated that "We must take the lead in addressing the challenge of global warming." In October 1993, President Clinton and Vice President Gore announced the release of the Climate Change Action Plan to demonstrate U.S. commitment to reducing greenhouse gas emissions to their 1990 levels by the year 2000. During 1993, President Clinton also signed the Convention on Biological Diversity, and his administration is actively working on negotiations of international agreements on desertification and forestry.

The U.S. Global Change Research Program (USGCRP), along with other programs within the newly formed Committee on Environment and Natural Resources Research (CENR), provides the research and information needs underpinning efforts to move toward a sustainable and environmentally sound future (see figure). The USGCRP was formalized through the Global Change Research Act, which was adopted by the U.S. Congress in 1990, establishing a research program "aimed at understanding and responding to global change, including the cumulative effects of human activities and natural processes on the environment, [and] to promote discussions toward international protocols in global change research..." To meet these needs, the Clinton Administration is recommending a focused Global Change Research Program budget of \$1.8 billion for FY 1995. These funds will support a wide range of policy-relevant research programs by the United States, providing a major contribution to worldwide global change research efforts.

Research on global change is vital to the national interest. As Dr. John Gibbons, Assistant to the President for Science and Technology, recently stated in testimony to Congress, "... our international policy experiences over the past few years have amply demonstrated that U.S. global change interests are inexorably linked to our economic welfare and national security, and domestic and foreign policy considerations, and in many cases through formal international treaties and agreements."

\section{What is Global Change?}

Global change is a term intended to encompass the full range of global issues and interactions concerning natural and human-induced changes in the Earth's environment. The Global Change Research Act of 1990 defines global change as "changes in the global environment (including alterations in climate, land productivity, oceans or other water resources, atmospheric chemistry, and ecological systems) that may alter the capacity of the Earth to sustain life." Global change issues include understanding and predicting the causes and impacts of, and potential responses to: long-term climate change and greenhouse warming; changes in atmospheric ozone and ultraviolet (UV) radiation; and natural climate fluctuations over seasonal to interannual time periods. Other related global issues include desertification, deforestation, land use management, and preservation of ecosystems and biodiversity.

\section{Why is Global Change Research Important?}


The USGCRP provides scientific insight into the causes and effects of changes in the Earth system, especially those related to human activities, and is developing tools for assessing options for responding to global change. The Program supports investments in Earth-system science and research to help develop and evaluate the options for increasing the sustainability of human communities and protecting the environment. As the depth of understanding of these systems and their feedback grows, the research results provide increasingly valuable input to support national and international policy formulation, as well as input to evaluate the impacts and effectiveness of these decisions. Thus, long-term commitment to a research program in global change provides the foundation for understanding and evaluating the changing world, and at the same time encourages wise decisions for the future of the nation and the international community.

\section{What Does the U.S. Global Change Research Program Do?}

Major foci of the USGCRP are: to observe and record what is happening to the Earth's environment; to understand why changes are occurring; to improve predictions of what will happen; to understand the consequences of change; and to develop capabilities for assessing change. Since its inception, the USGCRP has focused most intensely on:

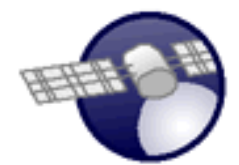

Supporting land-, ocean- and space-based systems

for observing global change:

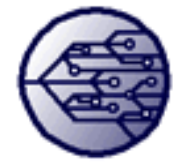

Developing worldwide data management and archiving systems and enhancing data accessibility;

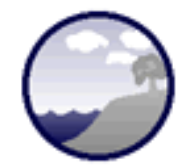

Supporting research on Earth system processes to improve the understanding of the most important physical, biological, and chemical processes that influence the global system; and

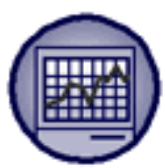

Supporting the development of integrative Earth system models for predicting the magnitude, timing, and extent of global change.

In response to new insights on the complexities of global change, the Program is expanding its efforts that are directed towards:

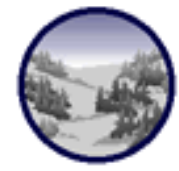

Analyzing the impacts and consequences of global

change on the environment and on society; and 


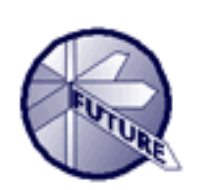

Developing tools for assessing national and international policies and options for responding to global change.

The USGCRP is organized under the auspices of the Subcommittee on Global Change Research (SGCR) of the National Science and Technology Council's (NSTC) Committee on the Environment and Natural Resources Research (CENR) [which has replaced the Committee on Earth and Environmental Sciences (CEES)]. Eighteen agencies, departments, and Executive Offices of the United States Government have joined together to plan and implement the USGCRP (Appendix D).

The USGCRP has been a major contributor to international scientific research on global change through support of international programs such as the World Climate Research Programme and the International Geosphere-Biosphere Programme. To strengthen the worldwide research effort, the U.S. also participates in numerous bilateral and multilateral research activities, including the establishment of regional research institutes, with the Inter-American Institute for Global Change Research beginning operations in 1994. The USGCRP joins organizations in other countries in providing scientific information for international science assessments, including those of the Intergovernmental Panel on Climate Change (IPCC) and the International Ozone Assessments of the World Meteorological Organization. In 1993, the USGCRP began to develop capabilities for conducting integrated assessments of global change and its consequences, with increased emphasis on understanding the social dimensions and economic implications of global change.

During the first half of 1994, the USGCRP will prepare a ten-year research plan, as called for in the Global Change Research Act. This new research plan will detail the integrated, interagency strategy that underlies the wide range of activities sponsored by the program and propose new areas for emphasis. Since the last major research plan was submitted with the FY 1991 budget, understanding of how the global system can be influenced by the use of fossil fuels, changes in land use (including deforestation), and release of industrial chemicals has increased. In the 1994 Research Plan, more emphasis will be placed on characterizing the nature and scope of global changes, what the magnitude and significance of changes will be, and what decision tools are needed to evaluate the choices that are available to adapt to and mitigate potential changes.

The new plan will reflect this broadening in focus, recommending expanded research efforts that improve understanding of the environmental and socio-economic consequences of global change and helping to explore the strengths and weaknesses of various approaches and policies for dealing with global change. The plan will also propose mechanisms (e.g., milestones) for measuring the progress of the integrated set of agency programs in addressing the science and policy questions critical to the USGCRP. In preparing this plan, the SGCR will be seeking input and review from national and international policy and research communities, from the executive and legislative branches of the U.S. Government, from industry, and from public and private interest groups.

\section{What are the United States and the International Community Doing About Global Change?}

The U.S. Government is working with other nations to address the issues associated with global change. The U.S. is one of many nations that have signed and ratified the Montreal Protocol on Substances that Deplete the Ozone Layer and subsequent amendments, the Framework Convention on Climate Change, and the Convention on Biodiversity. Along with other countries, the U.S. is working to develop other international agreements on desertification and the protection of forests. President Clinton's announcement on April 21, 1993, committed the United States to return greenhouse gas emissions to 1990 levels by the year 2000, and 
the release in October of the U.S. Climate Change Action Plan indicated how the U.S. intends to accomplish this. The U.S. is also developing long-term economic and technology-based strategies to enable progress to continue on greenhouse gas reductions into the next century.

To look more broadly at global environmental change, the Clinton Administration has established the National Council on Sustainable Development, whose members include senior representatives from within and outside the U.S. Government. The President is also proposing revised regulations and supporting legislation to preserve old-growth forests, to better care for government-owned range lands, and to ensure preservation of wetlands, while continuing to promote a growing economy. Thinking and researching globally while acting regionally and nationally, this Administration is looking toward a sustainable future for the people and the environment of the U.S. and the world.

Through the development of regional institutes such as the Inter-American Institute for Global Change Research, the SysTem for Analysis, Research and Training (START), and the U.S. Country Studies initiative, the USGCRP is working with developing countries on vulnerability assessments and defining options for responding to global change. The U.S. Government is refocusing foreign aid assistance to encourage the promotion of sustainable technologies, such as those related to renewable energy.

The USGCRP agencies are committed to a research program that can provide information for national and international policy formulation. To strengthen the science/policy linkage, the USGCRP is intensifying efforts to improve communication with decision makers and to identify those information needs that have the most significant implications for near-term policy development. The USGCRP is increasing support for researchin the areas of: social, economic, health, and policy sciences; understanding the interactions of terrestrial ecosystems with global change; understanding and predicting the environmental impacts of global change; and developing tools for conducting assessments of global change. In addition to focused USGCRP research activities, contributing research is directed toward developing more efficient and cost-effective technologies for energy, transportation, manufacturing, environmental controls, and information transfer (see figure).

This report provides background information on the most critical issues in global change, outlines the framework that is used to develop policy-relevant information, highlights how the USGCRP contributes to this expanding knowledge base, and describes international linkages and education and public outreach efforts. Appendices present agency-by-agency budget information ( $\underline{A}$ and B), a listing of acronyms (C), USGCRP subcommittee members (ㅁ), and USGCRP management and implementation (E).

\section{Go to Chapter 2}

Return to the Table of Contents

Return to the GCRIO Home Page 


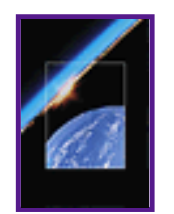

\section{Our Changing Planet FY 1995}

\section{ADDRESSING CRITICAL GLOBAL CHANGE ISSUES THROUGH A RESEARCH FRAMEWORK}

Global change research provides scientific insight into critical issues and policy choices facing the nation and the world community (see figure). Global change research to address these issues is organized into a flexible, multidisciplinary framework for coordinating science activities.

While human activities have long influenced local environments where people live, only since the start of the Industrial Revolution and the rapid population explosion have human activities begun to significantly influence the global environment. Measurements indicate that these activities are inducing changes in the Earth system which may have significant environmental consequences.

\section{WHAT ARE SOME OF THE CRITICAL GLOBAL CHANGE ISSUES?}

Over the past two decades, a number of specific issues have gained significant attention and served as the foci of global change research. Critical issues attracting attention include:

Climate Change and Greenhouse Warming, which relates to the potential for greenhouse gases and aerosols emitted as a result of human activities to alter the global climate and cause significant impacts on the natural environment and societal activities;

Ozone Depletion and UV Radiation, which relates to the effects of emissions from human activities on the atmospheric ozone layer, and the consequent reduction in the ability of the atmosphere to screen out ultraviolet (UV) radiation; and

Significant Variations of the Seasonal Climate, which relates to the agricultural, economic, and related effects on human activities of sharp fluctuations and variations in the seasonal to interannual climate, particularly the extended heavy precipitation and drought episodes associated with El Niñ o-Southern Oscillation (ENSO) events in the tropical Pacific Ocean.

These three issues are by no means the only issues of global environmental concern. Extension of agriculture and rapid increases in population are leading to major changes in land use, including deforestation and dryland degradation, which often have detrimental effects on the resilience and complexity of ecosystems. 
The development of coastlines is altering beach processes, reducing coastal habitats, and making communities more vulnerable to severe weather and sea level change. USGCRP agencies support additional research directed toward better understanding of these issues.

To meet the challenge of a changing environment, it is essential to continue to undertake research to improve the predictions of consequences and the effectiveness of options for responding to the impacts of global change.

\section{Climate Change and Greenhouse Warming}

Human perception of climate is the result of many local and time- varying experiences, ranging from daily variations in rain and shine to yearly variations in the intensity of the seasons. Climate influences the local nature of clouds and storms, the quality and quantity of water resources, the productivity of agricultural regions, and other activities of societal concern. Agricultural productivity and economic activities are closely tied to the seasonal climate, and can be significantly affected by the extremes of floods, drought, and severe weather, as well as the steady change of average climatic conditions. Although different climates have existed in the past, it is the projected increase in the rate of change and its global extent that make climate change a critical issue.

Increases in the concentrations of $\mathrm{CO}_{2}$ and other gases are enhancing the Earth's greenhouse effect, the popular term for referring to the trapping of infrared (heat) energy in the atmosphere. In the absence of offsetting factors such as variable solar radiative output, climate models predict that increases in greenhouse gas concentrations will raise the temperature of the Earth with potentially disruptive consequences. Reconstructions of past changes in climate over the Earth's history and theoretical understanding of how atmospheric, oceanic, and biological processes combine to determine the climate suggest that the increase in global average temperature may reach $1.5-4.5^{\circ} \mathrm{C}$ over the next century; in addition, zones of significant precipitation may shift, generally poleward and perhaps closer to coastal regions. Recent evidence, however, has shown that increases in atmospheric aerosols, which can scatter solar energy and alter cloud cover, may offset some of the effects of increases in greenhouse gas concentrations. Because of the inhomogeneous distribution of aerosols and because of uncertainties in their influence on cloud formation and hence on radiative transfer, their impact on climate remains difficult to quantify (see discussion of Volcanic Cooling).

The U.N. Framework Convention on Climate Change is prompting governments to contemplate (and take) action to reduce greenhouse gas emissions. To establish the scientific basis for national and international policy formulation and decisions relating to human- induced emissions of radiatively-active substances, it is necessary to monitor and understand the changes in concentrations of radiatively- active gases and aerosols in the Earth's atmosphere and to quantify the effects of those changes on the radiative forcing of climate. Greenhouse gases of major policy significance include $\mathrm{CO}_{2}, \mathrm{CH}_{4}, \mathrm{~N}_{2} \mathrm{O}$, the CFCs and their substitutes, and ozone in the lower stratosphere and troposphere. The atmospheric concentrations of all of these gases are changing as a result of human activities. Recent findings have provided important new insights:

- Carbon Dioxide. The atmospheric concentration of carbon dioxide $\left(\mathrm{CO}_{2}\right)$ has risen about 30\% since the 1700's. This increase is responsible for more than half of the enhancement of the trapping of infrared radiation due to human activities. Over the past two years the rate of rise in the $\mathrm{CO}_{2}$ concentration has, surprisingly and inexplicably, slowed. There is reason to believe that this reduced rate of increase in $\mathrm{CO}_{2}$ concentration may be short-term. New measurements are refining estimates of ocean uptake, but important uncertainties remain about uptake of $\mathrm{CO}_{2}$ by terrestrial vegetation and soils.

- CFCs. Because CFCs are believed to destroy lower stratospheric ozone, which is also a greenhouse gas, the net effect of CFCs as greenhouse gases is less than previously believed. Observations show the 
rate of increase of CFCs in the atmosphere to be slowing, consistent with international emissions controls, although stratospheric ozone depletion continues to occur.

- Methane. The atmospheric lifetime of methane $\left(\mathrm{CH}_{4}\right)$ has been determined to be $25 \%$ longer than previously thought, which contributes to raising its global warming potential (GWP). New research has shown that while wetlands are a significant reservoir for carbon, methane emissions from wetlands may increase with increasing $\mathrm{CO}_{2}$ concentration in the atmosphere. Over the last few years, the rate of increase in atmospheric methane has slowed. In 1992, the rate of increase was sharply reduced, but current measurements indicate that it is returning to earlier values. Continued research is needed to understand whether the reduced rate was due to reduced human emissions or to an enhancement of sinks.

- Ozone. Tropospheric ozone is an important greenhouse gas, and its influence is greatest in the upper troposphere. Calculations suggest that increases in tropospheric ozone can substantially increase radiative forcing. However, trends in tropospheric ozone still have considerable uncertainty. Field measurements demonstrate that most tropospheric ozone over the temperate North Atlantic Ocean is derived from transported North American precursors (nonmethane hydrocarbons and reactive nitrogen compounds).

- Very Long-Lived Greenhouse Gases. The lifetimes of fully-fluorinated ("perfluorinated") hydrocarbons (PFCs), such as $\mathrm{CF}_{4}, \mathrm{C}_{2} \mathrm{~F}_{6}$, and $\mathrm{C}_{6} \mathrm{Fl}_{4}$, have been shown from laboratory and modeling studies to exceed a thousand years. Understanding their chemistry and lifetimes is critical because some have been proposed as CFC substitutes, while others are emitted as trace products of industrial processes, including aluminum production.

- Aerosols. Modeling studies suggest that, in contrast to greenhouse gases, anthropogenic sulfate aerosols can lower surface temperatures. Research on the radiative effects of atmospheric aerosols resulting from emissions from coal and oil combustion and heavy industrial processes is important to understanding whether aerosols may be, in the near-term, counterbalancing the enhanced greenhouse effect of carbon dioxide. The absence of measurements confirming the predicted increase in land surface temperatures in the Northern Hemisphere appears to be most related to recent increases in the frequency of cloud cover. Recent studies suggest that the hemispheric asymmetry in this century's warming may be due, at least in part, to the preferential presence of sulfate aerosols in the Northern Hemisphere as a result of industrial emissions patterns. For carbonaceous aerosols emitted by biomass burning, the sign of their climatic effect is less certain, as predicted by the research results.

\section{Climate Change Impacts}

The changes in concentrations of greenhouse gases are predicted to induce a wide range of climatic changes in addition to global warming. Warming of the oceans and the melting of icecaps and glaciers will result in sea level rise. The amount of sea level rise over the next century is projected to be tens of centimeters (several times the rate of rise in the recent past), at the very least increasing the threats to coastal areas from storms and hurricanes (see figure). Prospective shifts in precipitation patterns are predicted by some models to lead to important shifts in world agricultural regions and in the availability of water resources, with the possibility of altering long-established patterns of land use. At the same time, the growth rate of plants under some conditions can be increased in the presence of additional $\mathrm{CO}_{2}$, and forests and grasslands can also be affected by increased $\mathrm{CO}_{2}$ and shifted precipitation patterns. Together, these changes have the potential to cause important shifts in flora and fauna. It is vital to understand what the vulnerabilities and capabilities of these systems to adjust are, and how their resilience to change can be enhanced.

Because projected acceleration in the rate of change is vitally important, it is essential to explore national and international options that may be available for reducing the extent and momentum of human influences on 
global change. One aspect of such an effort is the development and utilization of new technologies. In the energy sector, contributing research is underway to develop alternative technologies that are renewable and more sustainable; in the agricultural and food supply sector, new efforts are ongoing to improve crops and their resistance to pests and other stresses. Another aspect of exploring response options depends on improving the capability to understand and predict human behavior and to understand the abilities and willingness of societies to change, both sociologically and technologically. The FY 1995 USGCRP budget proposes more concentrated research on the economic and social effectiveness of potential policy options, especially those that encourage more sustainable patterns of resource use and management.

\section{Stratospheric Ozone Depletion and UV Radiation}

Ozone-layer depletion, the associated increase in ground-level ultraviolet radiation, and the impacts on human health and biota are significant environmental problems (see discussion of UV Monitoring). Human-produced chemicals containing chlorine and bromine, collectively referred to as halocarbons, are depleting the stratospheric ozone layer. Even if the control measures of the United Nations Montreal Protocol (1987) and its amendments are fully implemented, ozone depletion will continue for nearly another decade. Because of the long atmospheric lifetimes (up to 100 years) of many of the halocarbons, the earliest recovery from the Antarctic ozone "hole" is several decades away, and a return to near the natural atmospheric levels of chlorine and bromine, and therefore of ozone, will take centuries. Ozone-layer depletion is also known to be linked to global climate change. National and international decision makers continue to turn to the scientific community for predictions of the future condition of the stratospheric ozone layer and for scientific advice on how best to manage its rehabilitation.

Very recent measurements have shown that the rates of increase of CFCs and halons are beginning to slow, while substitute CFCs are beginning to accumulate in the atmosphere. These results, documented through a worldwide measurement network, verify that international decisions regarding emissions controls are beginning to have effects on atmospheric halogen levels.

Long-term global satellite and ground-based monitoring activities have demonstrated that stratospheric ozone depletion is occurring over most of the globe, except in the tropics. Downward trends of several percent per decade are now observed in all seasons at mid- latitudes (poleward of $20^{\circ}$ ), with winter and springtime declines of as much as 6 - $8 \%$ per decade observed poleward of $45^{\circ}$. Global ozone depletion was observed to be significantly worse in 1992 and 1993, including wintertime depletions of up to 25\% over populated regions in the high latitudes of the Northern Hemisphere.

The observations of unexpected and unprecedented ozone depletion in the past two years, coinciding with the period following the eruption of Mt. Pinatubo, have revealed new gaps in understanding and, hence, in prognostic capabilities. While ozone levels may have been perturbed by the Mt. Pinatubo eruption, either by changes in stratospheric temperature and/or circulation, or by enhanced heterogeneous chemistry, the magnitude and timing of the recent, large ozone decreases are not fully explained by the current understanding of these effects. Consequently, evaluation of the heterogeneous chemistry associated with surface reactions on aerosols through laboratory studies, atmospheric observations, and modeling remains a key research priority that requires an enhanced focus.

Stratospheric ozone depletion is linked to changes in the surface climate. Loss of lower-stratospheric ozone is predicted to lead to a cooling tendency at the surface. As a result of this effect, ozone decreases offset some of the greenhouse warming of the halocarbons that caused the ozone change. Such indirect couplings complicate projection of changes in the global climate.

\section{Significant Variations of the Seasonal Climate}


Variability within the natural climate system is historically perhaps the single most fundamental environmental factor affecting the course of human development. Societies, economies, and cultures throughout the world have been developed based in large part on the effectiveness of their ability to adapt to their climate. When temperatures and precipitation patterns depart significantly from historical means, the consequences, especially if unanticipated, can be catastrophic. Examples of the global implications associated with year-to-year variations in the climate include extreme drought such as that experienced in southern Africa in 1991-92; severe flooding, including the recent deluge in the midwestern United States; and complete elimination of critical sectors of national economies, such as the 1972-73 collapse of the Peruvian anchoveta fisheries.

Successful simulation of the mutual evolution of the atmosphere and ocean through coupled modeling has yielded a demonstrated capacity to predict the onset of the ENSO warm events, known to be central to short-term variability in the Earth's climate system. Progress in climate prediction has been stimulated by the development of a variety of models used for simulating ENSO events, by empirical studies that have better defined the global impacts of ENSO, by theoretical studies that have elucidated the underlying oceanic and atmospheric processes accounting for the predictability of ENSO, and by the development of substantially improved observing capabilities in the Pacific for initializing and verifying models under development for ENSO prediction. Compared to the early 1980's, when observational techniques were inadequate even to monitor the evolution of an ENSO event once underway, observations are ongoing to detect day-to-day changes in surface winds, sea surface temperature, upper ocean thermal structure, and ocean currents on a basin scale in the tropical Pacific. The capability to forecast the onset of ENSO phenomena, up to a year in advance, represents a near-term return on the USGCRP investment (see discussion of ENSO Forecasts).

To ensure that advances in climate prediction continue and are most appropriately suited to the specific needs of affected populations, a Seasonal-to-Interannual Climate Prediction Program (SCPP), based on the evolution of existing USGCRP program efforts to observe, research, model, and assess the ocean and the atmosphere, is currently being established. The Program will be based on an integrated approach that addresses climate variability from its origins in coupled atmospheric and oceanic behavior through its physical manifestations and socio-economic impacts. A fundamental component of the SCPP is the plan to establish a multinational network of research and application centers to develop and issue experimental seasonal to interannual climate predictions based on global ocean-atmosphere modeling of the ENSO phenomenon. The resulting forecasts will be disseminated to those nations and regions that are particularly impacted by climate variability associated with the ENSO phenomenon. International Application Centers will refine the global forecasts and tailor guidance to the specific conditions and needs of the localities they serve.

Many of the countries most affected by ENSO events are developing countries with economies that are largely dependent upon their agricultural and fishery sectors as a major source of food supply, employment, and foreign exchange. These countries often rely on a regular and predictable climate cycle (e.g., monsoon rains) to provide food and water for their populations. Climate information that can be used by local decision makers to prepare for anomalous precipitation and temperature patterns will provide the means to maintain and enhance their agricultural, fishery, and economic productivity.

This new ability to forecast seasonal to interannual anomalies accurately, along with strong indications of the potential for continued progress in predicting anomalies in mid-latitudes, represents a seminal contribution to the understanding of Earth systems processes. Through application of this new "technology," this scientific breakthrough can be turned into an effective tool that will contribute to the quality of human life, and to increased economic efficiency.

\section{What Research Framework Is Used To Address The Issues?}

The development of a predictive understanding of how human activities are affecting and affected by the 
Earth system is among the most complex of all scientific undertakings. This complexity arises for many reasons. Human influences and interactions with the global environment cover spatial scales from local to global and extend over time scales from days and seasons to decades and centuries, both back into the past and forward into the future. The influences and interactions involve all sectors of global society and all components of the Earth system, meaning that predictive capabilities must be developed for social and institutional systems as well as physical, chemical, and biological systems. Because the environment is so intimately tied to people's lives, all are impacted by any changes that might occur and all are interested in the character and quality of the predictions.

To ensure a coordinated focus that addresses questions ranging from understanding what is happening and what will happen, to determining what the societal consequences will be and what can be done to moderate or mitigate these impacts, the USGCRP is functionally organized into a framework of six coupled streams of research activity (see figure):

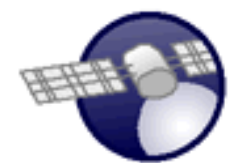

Observing the Earth System, which includes (i) establishing an integrated, comprehensive, long-term program of land-, ocean-, in situ, and satellite-based observations on a global scale that monitor and describe the current state of the Earth system and (ii) assembling and analyzing observations on recent and past social and environmental changes in the Earth system;

Managing and Archiving Information, which includes assembling, processing, storing, and distributing data and information that document the state of the global system, both the conditions of the natural system and of the societal systems that are influencing and are influenced by global environmental changes;

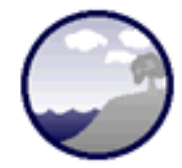

Understanding Processes, which includes conducting a program of focused studies to measure, analyze, and investigate the physical, chemical, biological, geological processes and societal influences that govern Earth-system behavior and the interactions of human activities with the global environment; 
of the atmosphere, oceans, and land surface to natural and human influences and to reconcile predicted and observed Earth-system behavior;

Analyzing Consequences, which includes evaluating and interpreting the environmental and societal consequences and impacts of global change and understanding the potential for natural and technology-enhanced adaptation to and mitigation of global change; and

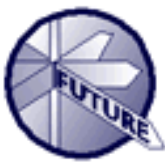

Assessing Policies and options, which includes research on social and economic interactions, decision frameworks (especially those which include decision making under uncertainty), and development of the policy and economic tools of analysis to examine the relative strengths and weaknesses of the various choices for responding to global change.

These streams of research activity are being designed and implemented to provide sound scientific information in support of national and international policy debate and decision making concerning the broad spectrum of natural and human-induced changes occurring in the global and regional environment.

To support coupling of USGCRP research activities to the national and international scientific community and the communication of research results to the public, the USGCRP includes two activities focusing on outreach and integration:

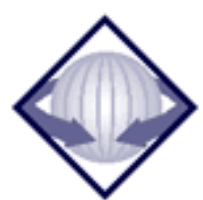

International Interactions, which includes encouraging and promoting cooperation with other nations in developing scientific understanding and establishing the institutional framework necessary for broad-based consideration of global change issues; and

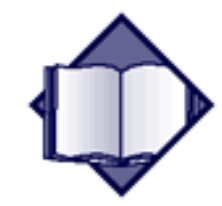

Education and Public Awareness, which includes preparing materials and organizing activities that promote consideration of global change and its human dimensions as part of both public awareness and educational processes. 


\section{How Will New Research Link To The Policy Process?}

Because of the need for improving understanding of the complex and diverse relationships between human activities and global change, the USGCRP will substantially increase support for programs that develop tools for assessing policies and options, especially in the area of integrated assessment methods. It also will increase support for research in the social, economic, and policy sciences, and for research that examines the impacts of and responses to global change. With higher levels of support, USGCRP programs will be able to improve understanding of the impacts of global change on human health, economic systems, settlements, and societal structures. Increased support in programs contributing to the USGCRP will also facilitate research on options for mitigation and adaptation strategies and the development of technologies to implement those strategies. Most significantly, new research in FY 1995 will result in better connection of research to policy making. Of special interest to policy makers will be the development of new decision analysis tools and methodologies for integrating assessments of global change, its impacts, and potential response options.

Linking research to policy requires the development of new programs on the human dimensions of global change. New social and economic research will focus on present and future patterns of greenhouse gas emissions, actions that can be taken to modify those patterns, and the effectiveness and potential benefits and costs of these actions. Contributing research will improve understanding of the effects on natural systems of factors like population growth, economic growth, technological change, and international trade.

Just as uncertainties remain with respect to the response of the climate system to changing emissions of greenhouse gases, important gaps in knowledge persist as to how people and institutions respond to changes in natural and human environmental conditions. These uncertainties will affect future levels of emissions, and they will influence the consideration and effectiveness of specific policies to reduce those emissions.

\section{Integrated Assessment Methodologies}

Integrated assessments bring research results from natural, social, and policy sciences into a framework that helps decision makers identify and evaluate actions to respond to environmental changes. Integrated assessments can help set priorities for the natural as well as the social and policy science research areas by providing information about the relative value to decision makers of information that is likely to result from research investments. Another major objective of integrated assessment is to develop information about interactions of complex, linked systems and problems and to make this information available in the decisionmaking process. Integrated assessments can advance the state of research by providing a framework for synthesizing findings and data from the physical, chemical, geological, biological, economic, social, and health sciences (see figure).

For FY 1995, the USGCRP proposes to markedly increase its support of integrated assessment activities. Some of the increase will support the development of methods and tools. One set of tools, integrated assessment models (IAMs), are an emerging type of model that link human forcing functions (e.g., greenhouse gas emissions), the effects of those forcings on the Earth-system, the resulting impacts on humans and ecosystems, and the economic and environmental consequences of potential responses. The models allow different global climate change policy options to be evaluated in terms of their influence on various parameters, such as their effect on Gross Domestic Product or employment. A number of the climate change IAMs have evolved from cost models developed primarily in the 1970's and 1980's that predicted emissions and calculated the cost of meeting various emission or concentration goals.

IAMs can be of various types, depending on the issue being addressed. Some IAMs are globally aggregated and do not, for example, distinguish the United States from the rest of the world. Such models can be used to study sequential decisions and the value of additional information. These models cannot, however, facilitate evaluation of policy instruments such as appliance efficiency standards, automobile efficiency standards, or 
having separate taxes on different fuels.

IAMs can also be spatially disaggregated, dividing the world economy into up to a few dozen regions. These larger models include more realism in their treatment of specific aspects, such as regional emission patterns and economic activity by sector. This type of IAM will be better suited to answer policy questions such as how to trade off the different greenhouse gases using economic as well as natural science criteria. For example, a biomass energy option or carbon sequestration program may become less effective if climate change is harmful to forest systems. Similarly, the model may indicate that international application of policies such as are required in the United States by the Clean Air Act may induce changes in future climate (e.g., through requirements for reduced emissions of particulate and sulfur) that need to be considered in evaluations of climate changes due to greenhouse gas emissions policies.

Phenomena associated with global change can affect currently stable regional environments and indigenous natural resources, and could have profound implications for land-use management. Regional-scale integrated assessment models are being developed based on detailed modeling of physical, chemical, geological, biological, and human systems. In many cases these models can define critical thresholds of environmental change. Early work is proceeding on such models for regions including the Great Lakes, the Great Plains, and the Southwest.

USGCRP support for integrated assessment methods will enhance efforts to develop reduced-form models that mimic the more complete natural science process models. The program will also encourage examination of a variety of methodological issues related to integrated modeling, including development of additional quantitative and qualitative approaches for integration. Related research will include: (a) modeling and evaluating the implications of rates of global change in addition to the extent of absolute change; (b) evaluating the impact of an increased frequency of extreme events; (c) uncertainty analysis of physical, economic, and biological parameters; (d) review of the successes and shortcomings of past integrated assessment studies (e.g., acid precipitation, stratospheric ozone, supersonic transport); and (e) comparison and evaluation of integrated assessment methodologies.

\section{Social, Economic and Policy Sciences}

USGCRP research in the natural sciences can provide only limited information for understanding the causes and impacts of, and societal responses to global environmental change. Research in the natural sciences needs to be integrated with research in the social, economic, and behavioral sciences, the policy sciences, and the health sciences in order to provide a more complete understanding of the human dimensions of environmental change. Current programs in the social and behavioral sciences focus on a number of areas of research including, but not limited to:

\section{International population trends and the human condition}

- What are the interactions between population growth/migration and environmental change?

- What demographic and social factors are particularly relevant for assessing the vulnerability of societies to environmental change?

- How do the health impacts of environmental change affect consumers and households?

\section{Patterns of trade and global economic activity}

- How do world economic growth and international trade patterns affect the use and value of environmental resources such as wetlands, coastal zones, and forest?

- What effects might large-scale, debt-for-nature swaps have on global environmental resources?

- How will the development and diffusion of technology affect impacts from global changes?

- What effects might changes such as political and economic liberalization have on the use of 
environmental goods?

\section{Adaptation and mitigation, including environmental resource use and management}

- Under what conditions has adaptive behavior to environmental stresses been undertaken in the past?

- What are the costs and benefits of various policy approaches to influence the use of key resources such as land, energy, water, and coastal zones?

- How do institutional and legal rules affect the use of common property resources?

- What international mechanisms and processes can be used to build the international coalition needed to stabilize concentrations of greenhouse gases?

New research within the USGCRP will focus on activities that drive global change and which will be affected by it. A number of specific questions confront policy and decision makers in governments and in many different economic sectors as they consider the management and use of resources such as energy, land, water, soils, and forests. Foremost among these questions are "How is global change likely to affect the availability and quality of resources?" and "How will policies and actions designed to mitigate or adapt to global change affect the supply, cost, and use of resources?" Research on resource management is especially important in situations where resources have multiple uses (see figure). The vulnerability of large-scale resource management investments to global change, especially in developing countries where resource investments often provide critical and life- sustaining services, is another important issue.

Another priority is the valuation of environmental goods, services, and assets, which requires fundamental research on how changes in the availability and quality of these resources are understood and measured in social terms. Environmental accounting poses significant definition and characterization problems. Unlike economic systems, environmental systems do not have a calibrating mechanism such as market prices to determine relative unit values. While numerical values exist for environmental goods, the consistency and interpretation of these values is a problem. Existing techniques to measure environmental values, such as contingent valuation, will be the focus of further development, testing, and validation through research conducted as part of the USGCRP. Alternative paradigms of valuation, derived from other social and behavioral sciences that reflect the psychological, cultural, and ethical dimensions of environmental values, will be studied.

Policy science research within the USGCRP will also focus on data, analytical methods, computational issues, and modeling requirements of policy analysis. Significant data issues include availability, organization, validation, reliability, and use of expert judgment techniques to fill data gaps. Analytical issues include developing methods for extracting general relationships from case studies, which are important for historical evidence as well as for studies on environmental services and benefits.

\section{Related Research in Impacts, Adaptation and Mitigation}

Many programs relevant to impacts, adaptation and mitigation of global change are underway as part of efforts outside of the USGCRP. These programs contribute substantial information to global change issues. Programs on impacts examine effects of global change on the environment and society, including water quality and supply, agricultural systems, and the health and diversity of natural systems. Research in mitigation focuses on the reduction of greenhouse gases and ozone-depleting chemicals in the atmosphere by reducing emissions and increasing sinks for these gases. Research in adaptation focuses on developing technologies and modifying practices to cope with climate change and increased UV radiation. Adaptation and mitigation efforts also address costs and feasibility of alternative technologies and their transfer, and provide economic analyses of possible response strategies.

The President's Climate Change Action Plan, a \$280 million program in FY1995 (not part of the USGCRP budget), to limit greenhouse gas emissions to the atmosphere consists of almost 50 actions involving all 
sectors -- industry, transportation, homes, office buildings, forestry and agriculture. Several USGCRP agencies are participating in biennial reviews of progress under the Action Plan to report on emissions trends and to adapt existing programs to evolving circumstances. Improved land and agricultural management will be encouraged through technical and economic assistance to private, non-industrial landowners. New residential appliance standards and a renewable technology consortium are being established to encourage improved efficiency and commercialization of renewable technologies. Another program is encouraging the use of more energy-efficient lighting equipment.

Funding for greenhouse gas mitigation research to develop energy-efficient technologies for reducing emissions from all sectors is proposed to increase about 40\%. Examples include energy supply and fuel usage in the utility, industrial, commercial and residential sectors; process and operation studies in energy-intensive industries such as primary metals, chemical and petroleum, cement, and pulp and paper; fuels and efficiency improvements within the transportation sector, as well as transportation modes and influences of urban planning; energy consumption, biomass burning practices, and fertilizer usage in the agriculture and forestry; afforestation/reforestation efforts and maintenance of soil carbon pools; coal mining practices; and CFC alternatives and new refrigeration, air conditioning and fire-retarding technologies (see figure). This additional research, outside of the USGCRP, contributes, however, to the overall goals and objectives of the USGCRP.

Impacts and adaptation research includes understanding the effects of global change on water supply and quality; review of water utilization and related technologies; understanding the effects of global change on food, fiber and timber supply, and ways to reduce vulnerability in these areas; understanding vulnerability and adaptability of species habitats and maintaining the health and diversity of natural systems; understanding the interactions and effects of global change on humans; and researching human adaptability to change. The SGCR along with the CENR Subcommittee on Environmental Technologies and Engineering Research, is reviewing all activities within the Federal government that are important to understanding the impacts of global change, the potential for adaptation to changes that might occur, and means of mitigating change.

$\underline{\text { Go to Chapter } 3}$

\section{$\underline{\text { Return to Chapter } 1}$}

\section{$\underline{\text { Return to Table of Contents }}$}




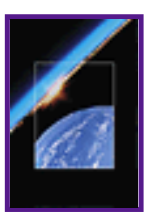

\section{Our Changing Planet FY 1995}

\section{The FY 1995 U.S. Global Change Research Program}

Each global change issue is addressed through a process which strives to document, understand, predict, and assess the science in a way that yields results which are relevant to the needs of decision makers. A framework of program elements for coordinating the USGCRP has been developed that expands on these research activity streams, building on the research architecture presented in previous USGCRP documents. The figure on the preceeding page represents the current set of sub-elements within the USGCRP research framework. This framework is being used to evaluate the research balance among Program components and to identify Program gaps. Reviewing the Program by framework element also helps to ensure that the overall USGCRP is well integrated nationally and internationally, and that individual elements of the Program are receiving the required attention and levels of funding. The proposed and ongoing research programs of the USGCRP are discussed below in the context of this framework. Many of these programs are linked to international efforts to address global change, as described in Chapter 4.

\section{Observing Global Change}

Continuation of efforts to develop a comprehensive program of land-, ocean-, airborne, and satellite-based observations on a global scale is critical to understanding and predicting global change. Some recent accomplishments and future plans for the observing program are highlighted below: (also see Recent Accomplishments in Observing Global Change)

\section{Space-Based Earth Observing System (EOS)}

In order to advance scientific understanding of the entire Earth system and to develop a deeper comprehension of its components and the interactions among them, it is essential that long-term, comprehensive global observations are collected, archived, and analyzed. To achieve this goal, U.S. agencies are cooperating with other countries in developing an international Earth Observing System (EOS). EOS is a series of polar-orbiting and low-inclination satellites that will provide global observations of the land surface, biosphere, solid Earth, atmosphere, and oceans for a minimum of 15 years.

EOS will greatly enhance the ability to understand and predict the effects of many parts of the Earth system (see EOS Satellites and Mission Objectives). These include:

- Hydrologic and dynamic processes, which control the Earth's temperature and the formation, 
maintenance, and dissipation of clouds and their interactions with solar radiation.

- Biogeochemical processes, which contribute to the formation, transport, and fate of trace gases and aerosols and their global distributions.

- Climatological processes, which govern the interactions of land and ocean surfaces with the atmosphere through the transport of water, heat, mass, and momentum.

- Ecological processes, which are affected by and/or will affect global change, and their response to such changes through adaptation and adjustment.

- Geophysical processes, which have shaped and continue to modify the Earth's surface through volcanism and melting of glaciers and sea ice.

Data from EOS platforms will be made available through the EOS Data and Information System (EOSDIS), which is discussed in the Data Management section of this chapter. Many of the accomplishments and program highlights included in this chapter are directly related to EOS and the series of Earth Probe missions that have been established to complement the EOS platforms. These missions are being conducted with substantial international cooperation and participation from European, Canadian, Japanese, and other space agencies from around the globe. The EOS-AM Series is scheduled for launch in 1998.

\section{Additional Space-Based Observations}

Currently, space-based observations are providing data on the following variables that are crucial to monitoring and understanding global change:

\section{Ozone and Other Trace Stratospheric Constituents}

The continuous global monitoring of stratospheric ozone levels is extremely important in providing decision makers information that can be used in international ozone assessments and for monitoring the effects of the Montreal Protocol on global ozone levels (see figure). Analysis of data from the Total Ozone Mapping Spectrometer (TOMS) instrument on the Nimbus 7 satellite showed that globally averaged concentrations of total ozone had decreased to unprecedented low values beginning in mid-1992 and continuing through early 1993. With the loss of operation of the Nimbus 7 TOMS instrument in May 1993, following 14.5 years of operation, the TOMS measurement sequence is being continued using the TOMS instrument aboard a Russian Meteor-3 spacecraft launched in August 1991. The Meteor-3 TOMS mission continues to be an excellent model for Russian-U.S. cooperation. Data are received and independently processed by Russian and U.S. scientists. Due to close collaboration between the two groups, almost $100 \%$ of the data have been captured and processed.

Preliminary Meteor-3 TOMS results showed that the record low globally averaged total ozone amounts continued until the summer of 1993, when values began to approach pre-1992 values. The Meteor- 3 data are being reprocessed to improve their accuracy so that more quantitative comparisons can be made with data from Nimbus 7. Record low average total ozone amounts in the important 30-60 ${ }^{\circ}$ north latitude band, which encompasses most of the U.S. as well as Europe, were also observed in this period. It is thought that these low levels may have been caused, in part, by the eruption of the Philippine volcano Mt. Pinatubo in June 1992. Aerosol concentrations resulting from the Mt. Pinatubo eruption were tracked globally by SAGE II and correlate well with low ozone measurements. Because of its high sensitivity to aerosols, its $1>\mathrm{km}$ vertical resolution, and its inherent self-calibration, the SAGE II instrument has provided a valuable database useful for long-term studies of atmospheric aerosols. To sustain the observation record, follow-on TOMS instruments are being prepared for launch on an Earth Probes Satellite in 1994, and on the Japanese Advanced Earth Observing Satellite (ADEOS) mission scheduled for launch in February 1996.

The Upper Atmosphere Research Satellite (UARS) has been providing a wealth of new information about the stratosphere and mesosphere since it was deployed from the space shuttle Discovery in 1991. The UARS Microwave Limb Sounder (MLS) continues to provide global maps of $\mathrm{ClO}$, the radical which is responsible 
for the Antarctic Ozone Hole. MLS measurements show the very high levels of ClO which are produced annually in the Antarctic and Arctic winter stratospheric vortices. Cryogenic Limb Array Etalon Spectrometer (CLAES) observations of the reservoir ClONO2 complement the MLS ClO observations. The springtime formation of ClONO2 in the Northern Hemisphere prevents the rapid ozone loss seen above Antarctica from taking place above the Arctic. The first global mapping of polar stratospheric clouds, which provide the surfaces needed for chemical reactions that release $\mathrm{ClO}$ from the chlorine reservoirs, have been provided by the Improved Stratospheric and Mesospheric Sounder (ISAMS) and by CLAES. Our understanding of the polar processes has also been increased by the UARS observations from these instruments.

The Space Shuttle has been an extremely effective platform for measuring trace stratospheric constituents. The second flight of the Atmospheric Laboratory for Applications and Science (ATLAS) took place aboard the Space Shuttle in April 1993, and a third flight is scheduled for October 1994. This will be the first flight of ATLAS during the peak of the ozone depletion season over Antarctica. In addition to the multiple instruments viewing the atmosphere, space plasma, and the Sun from ATLAS, this October mission will deploy the retrievable, German-built Shuttle Pallet Satellite (SPAS) carrying two instruments to make unique infrared measurements of the atmosphere and the first space-based observations of the critical chemical radical, $\mathrm{OH}$. One ATLAS instrument, the Shuttle Solar Backscatter Ultraviolet Spectrometer (SSBUV), will also fly in March 1994 and will provide highly calibrated measurements in support of atmospheric ozone monitoring. In addition to U.S. developed instruments, the ATLAS/SSBUV payload includes instruments from Germany, France, and Belgium, with participation from Switzerland and the Netherlands.

\section{Sea Level, Ocean Topography, and Ocean Color}

TOPEX/Poseidon, a joint U.S./France mission, is making global sea level measurements with unprecedented accuracy, allowing scientists the first opportunity to analyze the full spectrum of global signals. The annual variation in hemispherically-averaged sea level was found to be larger in the Northern Hemisphere than Southern Hemisphere by a factor of two, reflecting the influence of the large land mass in the Northern Hemisphere. This asymmetry has not been observed in previous altimetry data due to orbital uncertainties.

TOPEX/Poseidon has also produced the first realistic, large-scale, global ocean dynamic topography. This dynamic topography has been found to improve the estimate of the general circulation of the North Atlantic Ocean based on in situ observations, by reducing the discrepancy between the estimate and the float observations. Preliminary results indicate that a global ocean tide model with an accuracy of $2 \mathrm{~cm}$ can be developed using the TOPEX/Poseidon data. The TOPEX/Poseidon data are also being assimilated into a global ocean GCM, and a global framework is being developed for integrating the WOCE and TOGA in situ data.

The Shuttle Imaging Radar-C (SIR-C) is scheduled for flights in April and August 1994 and will be used for geologic, hydrologic, and oceanographic studies. Because of its ability to image Earth through cloud cover and its sensitivity to surface roughness, soil moisture, and sea-ice-water contrast, it is useful in studies of geological features, canopy morphology, sea-ice dynamics, and ocean surface temperature. The Lidarin-space Technology Experiment (LITE) will fly in September 1994 and demonstrate the utility of a space-based light detection and ranging (lidar) instrument for observations of aerosols, clouds, and surface albedo.

The development and launch of the Sea- viewing Wide-Field-of-view Sensor (SeaWiFS) will assist researchers in understanding the primary productivity of the upper oceans and the fluxes of carbon dioxide and other trace gases across the sea-air interface. SeaWiFS is scheduled to be launched in the Fall of 1994, and will provide the science community with the first space-based ocean color measurements since 1986.

\section{Air/Sea Interactions}

Surface winds over the oceans can significantly affect ocean currents, water vapor content in the atmosphere, and biogeochemical cycles. In order to acquire data crucial to understanding these interactions, the NASA 
Scatterometer (NSCAT) is currently being integrated and tested for inclusion in the Japanese ADEOS mission scheduled for launch in 1996. It is the only instrument currently under development that will be capable of acquiring measurements of wind direction and velocity under all weather conditions.

\section{Solar Irradiance}

Because total solar irradiance provides the driving force for the Earth's climate system, it is very important to establish and maintain a long-term record of this energy source. Active cavity radiometer instruments have been flown on a number of research satellites to initiate such a measurement record. The longest continuous record is the 14-year data set of the Nimbus-7 Earth Radiation Budget (ERB) solar measurements, which began in late 1978 and ended in early 1993. Overlapping that record are the Solar Maximum Mission (1980-1989) and the Earth Radiation Budget Experiment (1984- present) total solar irradiance measurements. In addition, an active cavity radiometer is currently operating on the Upper Atmosphere Research Satellite (UARS). Covering the 11-year solar cycle, these measurements show that on this time scale total solar irradiance variations are smaller than anthropogenic climate forcing and are too small to have a significant effect on climate. Nevertheless, it is important to maintain the data record because variability on longer time scales may be larger in magnitude and can potentially cause significant climate response. In fact, total solar irradiance variations are suspected of being one of the causes of past global climate changes on decadesto-century time scales. In the future, total solar irradiance measurements are planned on the Solar Heliospheric Observatory (SOHO) and EOS CHEM satellite missions.

\section{Precipitation}

Rainfall is one of the most important parameters which determines climate and, because it is one of the most variable, climate change. The dynamic and thermodynamic processes which generate rainfall are central to the dynamical, biological, and chemical processes in the atmosphere, in the oceans, and on the land surfaces. Latent heating, the primary internal source of energy for the atmosphere, occurs primarily during the process of condensation of water vapor to liquid water and its subsequent precipitation. It is thus essential to quantify the rainfall (and the energy it releases) in order to understand: (1) the dynamics that produce clouds, and circulations and convection that transport and mix minor constituents in the atmosphere; and (2) precipitation patterns that cool the land surfaces, nourish the biota, and generate the haline circulations in the oceans. The Tropical Rainfall Measuring Mission (TRMM), a joint mission between the U.S. and Japan, will aid substantially by quantifying the distribution of the two-thirds of global precipitation estimated to fall in the tropics and subtropics. TRMM is progressing toward a 1997 launch and a three-year mission life, and will provide data to improve climate models by quantifying the energy released by rainfall. This information is critical in understanding the ENSO phenomenon, which is responsible for interannual climate variations that produce drought, storms, and floods on a global scale.

\section{Land Cover and Vegetation}

USGCRP agencies cooperated with the European Space Agency, the International Geosphere-Biosphere Programme (IGBP), the informal Committee on Earth Observation Satellites (CEOS), and more than 26 foreign ground-receiving stations in an 18-month experimental program to collect $1 \mathrm{~km}$ resolution Advanced Very High Resolution Radiometer (AVHRR) data for each daily pass of Landsat over the Earth's surface. More than 22,000 AVHRR scenes (almost 2 terabytes of data) were collected and archived, and a prototype one-month data set of global vegetation condition was prepared. The data are being used to produce products such as global land cover maps and for monitoring seasonal vegetation condition (greenness) and changes. Based on its initial success, the program is continuing, complementing the operational programs that collect global AVHRR data at 4 and $16 \mathrm{~km}$ resolution primarily for oceanic and atmospheric applications.

The Landsat Pathfinder Program has acquired over 1,000 Landsat Multispectral Scanner and Thematic Mapper scenes of the world's tropical forests between the early 1970's and the present. These scenes are being analyzed to determine the extent of deforestation at three epochs, the late 70's, the middle 80's and the present. Current estimates of deforestation are considerably lower than earlier estimates, which were based 
on statistical data and lower resolution remote sensing. These results suggest that carbon emissions from the region are lower than previously thought, thus reducing somewhat the magnitude of the apparent "missing carbon sink."

Data from Landsat are essential for study of land-cover change and deforestation and their impact on degradation of animal habitats and biodiversity. Plans are underway to restore implementation and management of the Landsat program in light of the Landsat 6 failure in 1993. The final arrangements will likely call for establishing a long-term plan that accommodates the continuity of observations in a manner consistent with current Landsat data, and that allows modernization of the Thematic Mapper sensor by capitalizing on new technology to reduce its mass, volume, and cost. Landsat 7 is scheduled for launch in 1998.

\section{Sea Ice Cover}

Recent accomplishments have significantly enhanced the ability to monitor global sea-ice cover and to investigate more thoroughly key processes, such as albedo feedback and ocean density modification, that are important to global climate. A sea-ice atlas was recently published which extended the time series of sea-ice cover to include 1973-1976 and 1978-1987. Current work will yield the complete time series 1973-1993, enabling analysis for trends in sea-ice cover. Automated techniques used to monitor detailed sea-ice characteristics and ice motion from SAR data and to estimate ice- surface temperature from AVHRR data have also been developed.

\section{Land- and Ocean-Based Observations}

Most measurements of local and regional climatic variables are taken primarily for weather forecasting and other purposes, and are not described here. The USGCRP augments these many contributing efforts with several special programs.

\section{Greenhouse Gases, Aerosols, and Ozone}

The atmospheric burden of aerosols from human activities continue to be quite high. Anthropogenic aerosols include sulfate aerosols, which are formed primarily from sulfur dioxide emitted from major urban and industrial complexes, and carbon-containing aerosols, which are emitted from combustion of fossil fuels and from biomass burning. The impacts of an increasing atmospheric aerosol burden, on a regional scale, include reduced solar radiation at the surface (which can lead to cooling), and changes in atmospheric dynamics (which can lead to variations in seasonal rainfall and temperature patterns). Within the U.S., aerosol measurements are made routinely as part of air quality programs. In 1995, the USGCRP is proposing to enhance efforts to develop a global observational data base by contributing significantly to the Global Climate Observing System (GCOS), an international program proposed by the WMO, ICSU, UNEP, and UNESCO, that will support observations and research on atmospheric clouds, aerosols, water vapor, radiation budgets, and ozone, as well as on critical ocean and land parameters important to global change.

The atmospheric burden of natural aerosols was reduced in 1993. Both space- and ground-based measurements showed that the volcanic aerosols injected into the stratosphere by the June 1991 eruption of Mt. Pinatubo in the Philippines are finally being removed from the atmosphere by natural processes. This has resulted in the return of the global average temperature to the warmer levels typical of the 1980's, and to a reduction in the sharp decrease in ozone concentration in the lower stratosphere that is thought to have been caused by volcanic aerosols.

Research is ongoing to establish a baseline of information about naturally forming aerosols in remote maritime locations to which the climatology of aerosols in more populated areas can be compared. The program, a cooperative effort between government laboratories and universities, includes ship cruises to gather information about aerosol formation in ocean areas of both hemispheres, and the establishment of several 
monitoring stations in both continental and maritime areas to provide long time series of aerosol data.

Atmospheric concentrations of greenhouse gases and ozone- depleting substances are monitored through an informal worldwide network of in situ and flask-sampling sites. Long-term measurements, from which global trends are inferred, include carbon dioxide, methane, nitrous oxide, and halocarbons. Significant recent findings include the following: (1) Measurements at globally distributed USGCRP observatories have revealed a sharp increase in atmospheric concentrations of HCFC-22, a major CFC substitute, demonstrating that these substances are beginning to accumulate in the atmosphere. A marked inter-hemispheric gradient has also been observed. These data not only provide an important check on the human use and atmospheric fate of this compound as called for by the Montreal Protocol, but also yield new information on transport between the two hemispheres; (2) Thousands of globally distributed measurements have shown that the rate of increase of atmospheric methane slowed down substantially during the last decade, suggestive, but not conclusive of, changes in human emissions; and (3) Observations in 1993 confirm a significant reduction in the rate of increase in the atmospheric carbon dioxide concentration. Annual increases in the mean concentration of $\mathrm{CO}_{2}$ were smaller in the years 1991 and 1992 than in any other year since continuous monitoring was begun in 1957. By 1993, the annual rate was about $25 \%$ of what it had been over the past decade. While $\mathrm{CO}_{2}$ accumulation varies from year-to- year, the magnitude and persistence of this reduction are unprecedented in the modern record, and is thought to be due to increased carbon storage in the terrestrial biosphere. Whether these changes will persist is an important, unanswered question.

The USGCRP participates with other nations in a worldwide network of Dobson spectrometers that monitor atmospheric ozone concentrations. Ozonesondes are also used to determine the vertical distribution of ozone in the atmosphere. In addition, strong support is provided for development and deployment of the Network for the Detection of Stratospheric Change (NDSC) of the World Climate Research Programme (WCRP). This network is designed for observing and understanding the physical and chemical state of the stratosphere, with special emphasis on the depletion of stratospheric ozone.

\section{Ocean-Climate Parameters}

Movement toward the Global Climate Observing System (GCOS) will continue to be fostered in FY 1995. One USGCRP contribution to this international activity involves a program of long-term ocean observations, with an emphasis on in situ measurements of key ocean-climate parameters. The ocean module will be provided by the evolving Global Ocean Observing System (GOOS). In FY 1995, planned GCOS activities include making the current TOGA Observing System a permanent element of a long-term global observing program in support of routine predictions of ENSO events and their seasonal to interannual climate implications. Reconstruction of the long-term climate record will continue with the assembly of major data records, including precipitation and surface and subsurface ocean parameters. In addition to providing needed data sets for climate application studies, activities to provide correlative in situ data such as surface radiation, aerosol, and precipitation measurements will also continue as a step toward better understanding factors inducing change.

\section{UV Radiation}

Significant increases in ultraviolet (UV) radiation have been observed in conjunction with periods of intense ozone depletion. The ozone hole over Antarctica, which in 1993 produced the lowest values of ozone ever recorded on Earth, also allowed record levels of UV light to reach Antarctica. At one Antarctic monitoring site, UV- B, the part of the spectrum most harmful to life, has been recorded at levels 44 percent higher than in 1992. Investigations are now underway on the impact that the increased UV might have on life on and around Antarctica, and on whether animals and plants may have mechanisms to avoid harm from increased UV. Studies have already estimated that UV damage has reduced the productivity of ocean phytoplankton-tiny plants that comprise the base of the food chain- by $6 \%$ to $12 \%$ in areas affected by the ozone hole. 
Substantial progress was made during FY 1993 in establishing a U.S. Interagency Ultraviolet (UV) Monitoring Network. Several Federal agencies are either currently operating or are developing UV monitoring networks. Because each of the individual agencies have different research and operational needs for UV data (e.g., concerns with effects on agriculture, on human health, and on fish and wildlife), each of these networks are using different types of instruments that best address their respective needs. The USGCRP's UV Panel is currently developing a UV monitoring plan to ensure that data collected by the individual agency networks are intercalibrated, interoperable, and easily available to the UV-data user community. A network calibration facility is being established in Boulder, Colorado to serve as the network's technical center. The UV Panel is also consulting with international organizations, including the World Meteorological Organization, to ensure that the U.S. UV monitoring efforts are coordinated with international programs. Version 1 of the UV monitoring plan is scheduled for completion in Spring 1994.

\section{MANAGING GLOBAL CHANGE DATA AND INFORMATION}

Global change research activities generate and require massive amounts of highly diverse data and information to document change, to improve understanding of global change processes, and to carry out integrated assessments of impacts on human affairs. Because global change issues are so broad, including human and natural forcing factors, ecological change, biodiversity, human interactions, and comprehensive assessments, the data and information management challenge is not only to archive, preserve, and make data available for individual research activities, but also to be able to combine data from various disciplines and disparate sources (see Recent Accomplishments in Global Change Data and Information Management. This capability to combine data and information into synthesized products will be a major factor in the ability of investigators worldwide to understand, predict, and analyze the multitude of issues related to the policy aspects of the program.

A major focus for data and information management efforts within the USGCRP is the development of the Global Change Data and Information System (GCDIS). The development of GCDIS is being coordinated with related activities within the U.S. Government (see U.S. Data Policy), including those of the Federal Geographic Data Committee and the emerging National Information Infrastructure, in particular with the Government Information Locator Service.

GCDIS will provide the infrastructure of the global change data and information management program. The U.S. Global Change Data and Information System Implementation Plan has been reviewed by the Committee on Geophysical and Environmental Data of the National Academy of Sciences and will be published in the spring of 1994. The GCDIS is a priority-driven system composed of individual agency systems made interoperable by the use of common standards and approaches, technology sharing, and data policy coordination. The GCDIS functions include setting priorities for individual data and information sets, identifying and/or developing those sets, and incorporating them and the necessary related services into GCDIS.

The Earth Observing System Data and Information System (EOSDIS), a component of GCDIS, is being built in an evolutionary manner, with new versions coming online to support launch of EOS platforms and to include technological innovations. EOSDIS Version 0, to be released in July 1994, will provide 'one-stop shopping' for data sets in the distributed data centers of EOSDIS, called Distributed Active Archive Centers (DAACs) (see figure). EOSDIS Version 1, scheduled for 1996, will provide faster, better user services and will include links to existing non-EOS data sets. In the pre-EOS time frame, EOSDIS will provide access to Pathfinder data sets, which are existing long-term satellite data sets used to generate consistent geophysical records.

Examples of other specific programs that contribute to GCDIS include the Geosystems Databases program, an effort to expand databases in the areas of documentation, networking, mass storage technology, and data 
intercomparisons. The Land Characterization and Data Management program will provide information about and access to global land data sets including vegetation index data derived from AVHRR data, Landsat MultiSpectral Scanner/ Thematic Mapper (MSS/TM) data, and global cartographic and vegetation data. In addition, post-1978 Landsat MSS and TM data will continue to be converted to stable storage media.

GCDIS will also include a number of long-term, retrospective data sets that are critical for evaluating climate variability and for use in detecting changes in the global climate. These data sets include historical global marine meteorological observations, global upper air data, global and regional variations of temperature and precipitation, global oceanographic data, global baseline data on atmospheric trace constituents, and global aerosol and ozone data sets. Major progress has also been made in the reprocessing of satellite data to provide the scientific community access to a longer and more consistent record of satellite measurements.

The Global Change agencies are developing new techniques for producing needed data sets. For example, a pilot project, completed in early FY 1994, demonstrated the value of reassimilating available data to provide retrospective records. The pilot project reanalyzed atmospheric observations taken from May 1982 through September 1983. The sources of data included satellites, pilot balloons, aircraft, and surface observations. Follow-on projects will reanalyze data from the 1950's to the present.

The first version GCDIS will be available in April 1994, accompanied by two interagency pilot projects:

- A GCDIS pilot project has been initiated to address user needs for carbon dioxide related data, images, and research publications. This pilot project will test most of the functional components of GCDIS. Specialized search capabilities will be developed for three classes of users: researchers, policy makers, and K-12 educators.

- A pilot project will be initiated in cooperation with a networked state library system to provide GCDIS access to local libraries, universities, community colleges, and secondary schools.

Efforts are underway to enhance the access of researchers and policy makers to socioeconomic and demographic data and information. New software programs are being developed that enable researchers to extract relevant information and conduct exploratory data analysis from the U.S. Census and its Public Use Microdata Samples (PUMS), which contain detailed socio-economic information based on 1\% and 5\% samples of the U.S. population. New databases are being developed that combine both physical and biological science data with socio-economic data. For example, worldwide data on income levels and product accounting now are linked with data on resources and soils. One valuable outcome of this new database is the ability to display agricultural land-use changes that are likely to result from changes in climatic conditions. Enhanced data and information products will contribute greatly to increasing understanding of global change.

\section{Understanding Global Change}

Advances in the worldwide understanding of global change come through analysis of data and results from existing data sets and studies of past changes in the global system, from current observing systems, from short- and long-term field experiments, and from simulations involving mathematical models. Process research focuses on fundamental processes and mechanisms that control the physical, chemical, biological, societal influences, and geological processes that govern Earth system behavior, including effects of global changes on natural systems and human activities. Improvements in the understanding of this wide range of processes are essential for improving the predictive models being developed to aid national and international policy makers in deciding which options to pursue in adapting to and mitigating impending changes (see Recent Accomplishments in Global Change Process Research).

Research within the USGCRP includes studies of the atmosphere, the ocean, the cryosphere (snow, ice, glaciers, etc.) (see figure), the lithosphere (land surface), and marine and terrestrial ecosystems. The domains 
and processes include a wide range of scales in time and space significant to understanding the Earth system.

In recognition of the importance of improving understanding of climate change and greenhouse warming, ozone depletion and UV radiation, and the large variations of the seasonal climate, modest augmentations of selected process research programs are proposed for FY 1995. These increases will enhance research on terrestrial ecology and on cloud and radiative transfer processes, and will continue to support research on global water cycles, atmospheric chemistry, and ocean ecology.

\section{Climate and Hydrologic Systems}

Research on climate and hydrologic systems has been one of the top priority science elements of the USGCRP over the last several years. This element includes research on processes that regulate the global energy and water cycles, including atmospheric radiation, clouds and precipitation, solar forcing, sea ice and sea level, the roles of the oceans and land-surface properties.

\section{Clouds and Radiation}

The first field site for the Atmospheric Radiation Measurement (ARM) Program, established in the area surrounding Lamont, Oklahoma, has started to provide detailed data for improving understanding of cloud and solar and infrared radiation processes in mid-latitude continental regions. This research is providing an intensive data set on cloud-radiation interactions, and will eventually lead to improved global atmospheric models for climate system research and prediction. The types of data being acquired include surface meteorological and radiation data, vertical profiles of the atmospheric parameters important to the atmospheric radiation balance, periodic aircraft-derived data on clouds and radiation, and satellite data from other programs that document the top of the atmosphere radiative fluxes.

Development of instrumentation for the ARM Program is extending the state-of-the-art in atmospheric remote sensing. The Multifilter Rotating Shadowband Radiometer, which represents one of the latest advances in surface-based radiometry, has been operating now for two years. In 1993, the newly developed Atmospheric Emitted Radiance Interferometer (AERI) Spectrometer was successfully deployed for testing. The measurements will be used to validate models simulating radiation fluxes and the profiles of water and other key atmospheric properties and constituents. Additional state-of-the-art instruments, including cloudand aerosol-sensing lidar instruments and cloud particle radar systems, are now being developed for the ARM Program.

A mission using an Unmanned Aerospace Vehicle is planned in 1995 to measure solar and infrared radiation at the top of the troposphere through several diurnal cycles. Through the Strategic Environmental Research and Development Program (SERDP), measurements using the top-of-the-troposphere platform will be coordinated with ground-based instrument data from the ARM site.

The four-month field phase of the TOGA Coupled Ocean Atmosphere Response Experiment (TOGA COARE) was success-fully completed in February 1993. The unprecedented effort involved hundreds of scientists, students, and technicians from 20 nations to measure moisture, momentum, and heat fluxes between the ocean and atmosphere in the western Pacific Ocean warm pool. The resulting data set is being used to improve the understanding and modeling of the energy exchange between the ocean and the atmosphere. Variations in the extent and duration of the intense exchange of energy between the warm pool and the overlying atmosphere appear to induce climate variations over the entire Pacific basin and beyond.

The Central Equatorial Pacific Experiment (CEPEX) was conducted in March and April of 1993 to examine the validity of a hypothesized thermostat effect which may limit greenhouse warming (see figure). Deep intensive convection is observed to occur when tropical sea surface temperatures (SSTs) exceed about $27^{\circ} \mathrm{C}$. This convection produces cirrus (ice particle clouds) anvils that spread out over millions of square kilometers. It is hypothesized that while cirrus clouds trap outgoing infrared radiation, they also reduce incoming solar 
radiation, the net effect being to stabilize SSTs, thereby acting in effect as a thermostat. CEPEX results will be available by the Spring of 1994.

\section{Water and Energy Balance}

Several projects which are part of the Global Energy and Water Experiment (GEWEX), of the WCRP, are contributing to the understanding of the diurnal and seasonal aspects of the water and energy balance. These studies are assessing the accuracy and resolution to which the components of the energy and water balances can be determined from in situ measurements, remote sensing retrievals, and the use of regional mesoscale climate models. As part of a series of regional studies taking place around the world, the GEWEX Continental-scale International Project (GCIP) is examining the energy budget and hydrological cycle of the Mississippi River watershed, which includes $44 \%$ of the land area of the continental U.S. and drains all or portions of 30 states. Other GEWEX projects include land-surface and cloud climatology studies using data from geostationary and polar-orbiting international satellites.

\section{Sea Level}

Melting of the Greenland and Antarctic ice sheets would raise sea level by some 70 meters, and yet it is still not known whether, as a whole, these ice sheets are currently growing larger or smaller. Comparison of Geosat and Seasat data suggest that parts of the southern Greenland ice sheet thickened by about 1.3 meters between 1978 and 1987, an average of $15 \mathrm{~cm} /$ year. Comparison of the aircraft laser data with surface measurements made in 1980 provides support for this result - this comparison suggests that the ice thickened by up to two meters between 1980 and 1993. Increases in the volume of the ice sheet could lead to a decrease in sea level; however, in the case of the Greenland ice sheet, the measured increases in thickness may be offset by ice sheet deterioration in marginal areas.

Airborne laser altimeters are being used to survey the Greenland ice sheet. Advances have been made in these airborne surveys so that they can now measure surface elevations on grounded ice sheets to an accuracy of tens of centimeters. Additionally, development of techniques for mapping ice sheets and measuring ice-stream motion from Landsat and SAR data has allowed compilation of the first SAR map of Greenland, which reveals a hitherto unknown ice stream some $50 \mathrm{~km}$ wide and $300 \mathrm{~km}$ long. These, and other achievements, will contribute towards development of a capability to monitor the mass balance of the polar ice sheets, and to understand what is causing observed thickening or thinning. In turn, this will lead to an improved ability to predict ice-sheet response to prescribed climate changes, and thus to estimate future changes in sea level.

\section{Seasonal to Interannual Variability}

The TOGA program, to conclude in 1994, has greatly enhanced understanding of the causes of seasonal to interannual fluctuations in the tropical Pacific. Analysis of results from the TOGA/COARE intensive observation period, coupled with model studies, are providing the basis for improving predictive capabilities. To extend the predictability of seasonal to interannual fluctuations beyond the tropical Pacific, the Global Ocean-Atmosphere-Land System (GOALS) program is being developed, which will contribute to the WCRP Climate Variability and Predictability Programme (CLIVAR). GOALS is intended to build upon the successes of ENSO research by extending predictability of seasonal to interannual fluctuations beyond the tropical Pacific to include the effects of the other tropical upper oceans, higher latitude upper oceans, and land surface processes. This program represents a focused U.S. effort to develop and improve models for forecasting seasonal to interannual precipitation anomalies like those in the Midwest last summer, seasons to years in advance.

\section{World Ocean Circulation}

Long term (decadal) changes in the ocean are being investigated through the World Ocean Circulation Experiment (WOCE) and the Atlantic Climate Change Program (ACCP). While it is known that the ocean and atmosphere interact strongly, the feedback mechanisms coupling them are inadequately understood. For example, it is believed that the ocean can act both as a heat sink and as a trap for atmospheric greenhouse 
gases, thereby slowing the rate of global warming. WOCE is designed to provide the data needed to improve and test the availability of models to predict long-term behavior of the ocean. ACCP, which contributes to the WCRP CLIVAR program, is focused on the particular relationship between the global climate and the Atlantic Ocean, the basin which has apparently been the most variable.

Improved understanding of the thermodynamics of the oceans is central to developing global models that predict the effects of global change on the Earth system as a whole. Evidence suggests that there has been a 35-year warming trend in the subtropical North Atlantic Ocean temperatures down to 2500 meters. There are also new estimates of vertical mixing in the ocean, and of heat transport across mid-latitudes in the South Pacific and South Atlantic, suggesting an imbalance between the Northern and Southern Hemispheres that may be compensated by changes in the Atlantic "conveyor belt" deep circulation. Changes in large-scale ocean circulation could be the cause of regional shifts in climate patterns.

\section{Atmospheric Chemistry and Biogeochemical Dynamics}

Quantitative understanding of the sources and sinks of atmospheric trace gases and aerosols and of the interactions which contribute to changes in biogeochemical processes are crucial for making reliable predictions of future concentrations of atmospheric greenhouse gases.

\section{Carbon Dioxide}

The annual increase in atmospheric concentrations of carbon dioxide is the difference between the emissions of $\mathrm{CO}_{2}$ from combustion of fossil fuels and biomass and uptake by oceans and the biosphere. It is believed that enhanced sinks for carbon are responsible for the recent slowdown in the $\mathrm{CO}_{2}$ increase in the atmosphere, but the exact cause remains unexplained (see Global Carbon Cycle).

Recent evidence suggests that in the short term, at least, the land sink may be larger than previously thought. Anomalies in surface temperature and precipitation may have allowed terrestrial ecosystems to accumulate more carbon in the period 1991 to 1993 than normally would have been the case. The cause of the anomaly is unclear, but the timing is coincident with the eruption of Mt. Pinatubo. One hypothesis is that lower temperatures at the Earth's surface temporarily reduced rates of respiration and thereby enhanced net carbon uptake.

Because few measurements of the carbon concentration in coastal oceans have been made, there is only limited understanding of the role of continental shelves in the exchange of carbon dioxide between the coastal shelf and the atmosphere above it, even though half of ocean photosynthesis is estimated to occur on continental shelves. A field research program is underway near Cape Hatteras, North Carolina that will provide important information for quantifying the processes which affect the cycling, flux, and storage of carbon and other biogenic elements at the land/ocean interface and for defining ocean-margin sources. Preliminary data on the $\mathrm{CO}_{2}$ gradient indicate that continental shelves such as the one near Cape Hatteras could be a relatively large sink for atmospheric carbon dioxide during certain times of the year.

To further refine estimates of the ocean sink, the Global Survey of $\mathrm{CO}_{2}$ in the Oceans (JGOFS) has now nearly completed its work in the Atlantic and Pacific Oceans, and is beginning work in the Indian Ocean. The Survey is being undertaken in conjunction with cruises of the World Ocean Circulation Experiment (WOCE). The goal of the survey is to obtain a high accuracy "snapshot" of the distribution of carbon dioxide within the world's oceans. An extensive data quality control program established at the start of the Survey included the provision of certified reference materials and certified analytical equipment. This has resulted in a data set of unprecedented accuracy.

The WOCE- $\mathrm{CO}_{2}$ survey data set will be used to calculate the exchange of $\mathrm{CO}_{2}$ between the ocean and the atmosphere. Together with models of the atmospheric transport of $\mathrm{CO}_{2}$, and with an improved understanding 
of the $\mathrm{CO}_{2}$ fertilization effect, these calculations will allow the locations and magnitudes of net sources or sinks of $\mathrm{CO}_{2}$ to be inferred on a planetary scale. The data set will also permit improved estimation of the uptake of fossil fuel $\mathrm{CO}_{2}$ by the oceans, both through modeling and through correlation with the distribution of other man-made compounds within the ocean.

\section{Ozone}

Ozone measurements suggest that tropospheric ozone derived from anthropogenic pollution may exceed that derived from natural sources over the North Atlantic. Long-range transport of continentally-derived precursors is estimated to account for as much ozone on a hemispheric scale as do natural processes. Because upper tropospheric ozone is an extremely potent greenhouse gas, national and international policy makers will need to consider global warming in the context of regional pollution abatement. These results were part of the IGBP International Global Atmospheric Chemistry (IGAC) Program to study the chemistry of the global atmosphere.

New areas of emphasis in ozone research include understanding the role of biomass burning and stratospheric inclusions in determining the high ozone concentrations seen over the South Atlantic. Field campaigns are underway in the tropics and at high northern latitudes designed to study boundary layer fluxes of ozone and exchanges with the free troposphere. Specific process research is being conducted on chemical mechanisms for ozone formation/destruction (sensitivity/uncertainty evaluation of known kinetics parameterizations and determination of unknown mechanisms); and on evaluations of the joint action of transport and chemistry in determining the state of mid-latitude, lower stratospheric ozone, through global models and other diagnostic tools.

\section{Perfluorinated Hydrocarbons}

Laboratory measurements have demonstrated that perfluorinated hydrocarbons (PFCs), which are greenhouse gases emitted as by-products of industrial processes such as aluminum production and proposed as CFC substitutes, persist in the atmosphere for thousands of years. As a result, their emissions into the atmosphere are essentially irreversible, and their contributions to global warming are inadequately characterized by short-time global warming potentials. Proper consideration of the environmental consequences of PFC emissions, therefore, imposes upon the national and international policy community a new requirement to grapple with extremely long-term effects. Refined methods for calculating ozone depletion potentials are being developed using atmospheric measurements rather than only model results.

\section{Aerosols}

Emissions into the atmosphere of aerosols, and gases that chemically react to form aerosols, can have direct effects both on the global radiation balance and on global atmospheric chemistry. Research on the physical and chemical characteristics of tropospheric aerosols is underway to determine whether changes in aerosol (and aerosol precursor) emissions may be, at least temporarily, hiding the warming effect of greenhouse gases. Research on the radiative effects of sulfate particles formed in the lower troposphere, mainly as a result of emissions from coal combustion, is important to understanding whether they may be, in the near term, counterbalancing the enhanced greenhouse effect of carbon dioxide. For aerosols emitted by biomass burning, the sign of their climatic effect is less certain, being dependent on the amount of black carbon in the aerosol. The absence of measurements confirming the predicted increase in land surface temperatures in the Northern Hemisphere appears to be most related to recent increases in the frequency of cloud cover. Recent studies suggest that the hemispheric asymmetry in this century's warming may be due, at least in part, to the anthropogenic aerosol emissions being largely in the Northern Hemisphere.

\section{Methane}

Atmospheric methane concentrations have been increasing at a reduced rate. The residence time of methane in the atmosphere has been found to be $25 \%$ longer than previously thought, however. Research is ongoing to quantify human-induced methane emissions from landfills, coal mines, natural gas systems, rice paddies, and 
biomass burning as well as natural emissions of methane from wetlands and other sources. The results of this research will provide baseline data to help understand the causes of the increasing concentrations of atmospheric methane and for identifying strategies for reducing emissions from various sources.

\section{Ecological Systems and Dynamics}

Regional measurements of $\mathrm{CO}_{2}$ uptake by forest vegetation suggest the net uptake of carbon worldwide could account for the estimated "missing" carbon in the global carbon budget. Based on almost two years of continuous measurements of $\mathrm{CO}_{2}$ exchange between the atmosphere and the vegetation and soils of Harvard Forest in eastern Massachusetts, the net annual uptake of carbon by the forest ecosystem was estimated to be as large as 4 tons per hectare. Confirmation of these results with other natural vegetation studies would support the use of forest management (including reforestation) as an interim mitigation strategy that is an environmentally attractive way of helping to reduce the buildup of atmospheric $\mathrm{CO}_{2}$. Uncertainties regarding the rate of deforestation, conversion of land to agricultural use, population growth, and land management practices make it difficult to estimate the extent to which forests can conserve or sequester large quantities of carbon on a global basis.

Five Boreal Ecosystem-Atmosphere Study (BOREAS) field campaigns will be conducted throughout 1994, starting with a winter campaign in February and ending with a September end-of-growing-season campaign. BOREAS is an international, multidisciplinary study to improve understanding of the exchange of gases, energy and water between the boreal forest biome and the atmosphere in order to clarify their roles in global change. It is sponsored jointly by agencies within the U.S. and Canadian Global Change Research Programs. Airborne and spaceborne remote sensing will be used to extend understanding of these processes from the local to regional scales.

Recent research has documented that the uptake of carbon by soils is a dynamic process that varies in relationship to soil age and type. Understanding the role of soils in the carbon cycle is critical to understanding how human activities, including agricultural and forestry practices, influence the fluxes of carbon from terrestrial ecosystems. Remotely sensed surface temperature over a $300 \mathrm{~m} \mathrm{~km}$ - by-300 km region in western Montana has shown that the ratio of surface temperature to a normalized difference vegetation index can distinguish wet and dry conditions in a forest. This ratio may have applications in climate models, research on decomposition, and monitoring of fire conditions.

\section{USGCRP Terrestrial Ecology Initiative}

The USGCRP proposes to augment ecological research through a Terrestrial Ecological (TECO) initiative in FY 1995. The initiative will focus on the effects of global change (e.g., climate) on ecosystems, and the feedback effects of ecological processes on atmospheric composition (e.g., greenhouse gas concentrations) and climate. Its scope includes research on how ecological processes are affected by altered atmospheric $\mathrm{CO}_{2}$ and other trace gases, by altered climate conditions, and by changing land-use patterns - all in relation to constraints of other resources (e.g., nutrients, water, light, etc.). This initiative also includes research on how ecological systems affect the exchange of $\mathrm{CO}_{2}$ and other trace gases with the atmosphere and ultimately determine terrestrial sources and sinks of carbon.

Implementation of the TECO initiative would include:

- Experiments that determine ecosystem responses to combined effects from global forcings of elevated $\mathrm{CO}_{2}$, temperature, water, and nutrients;

- Field studies designed to provide a predictive understanding of the combined effects of global forcing (e.g., climate change) and landscape-scale processes on the future structure and distribution of ecosystems; and

- Research to determine the potential effects of global forcing on the biodiversity (e.g., species diversity, 
genetic diversity, habitat diversity) of managed and unmanaged ecosystems, and in turn, what the resulting effects of biodiversity changes on ecosystem function will be.

\section{Human Interactions}

Human activities can greatly influence global change as well as be significantly influenced by global change. Changes in land use can be a major driving force of environmental change. Conversion of natural forests into croplands and human settlements, overgrazing of grasslands, intensive planting and fertilization of agricultural lands, and the world wide increase in population density can have significant impacts on the global carbon budget and fluxes of greenhouse gases. While the use of Landsat and other satellite data have been instrumental in monitoring land-cover change in many regions of the world, this type of observation does not provide detailed information about specific land management practices. The international Human Dimensions Programme plans to address questions regarding: (1) How has land cover been changed by human use over the last 300 years? (2) What are the major human causes of land-use change in different geographical and historical contexts? (3) How might these land-use changes affect land cover in the next 50 years? and (4) How might changes in climate and global biogeochemistry affect both land use and land cover?

The Consortium for International Earth Science Information Network (CIESIN) is supported by USGCRP agencies to assist in compiling global-scale time series and baseline data and information on the human component in global environmental change, to develop an advanced network for data access, to conduct research and analysis focusing on socioeconomic data, and to provide services through the Socioeconomic Data and Applications Center (SEDAC) Network to disseminate data. CIESIN has been working to develop informal international partnerships and an operational framework that allows user communities to share data and information electronically among international data archives and resource centers.

\section{Earth System History}

By reconstructing worldwide snapshots of past climates, scientists can test how effective climate models are in simulating past conditions and thereby improve the ability to model and predict the impacts of future changes in global climate. Evidence from ice cores, bogs, lake and ocean sediments, and glacial moraines document that the climate may have changed frequently and abruptly over the last few million years. Additionally, data from time series reveal previously unknown process relationships that help establish the rate of change within the climate system.

USGCRP agencies established the National Ice Core Laboratory at the Federal Center in Denver, Colorado. This is a facility for storing and studying ice cores recovered from the polar regions of the world.

Polar ice is an excellent recorder of climate history, and provides the only known continuous, direct recorder of paleoatmospheric composition. Recent results from the analysis of Greenland ice cores have revealed that rapid changes in climate may have occurred over time periods less than a decade, and that these changes are probably associated with "switching" between stable ocean modes, a "switch" that may have been triggered by sea-ice conditions.

Research is underway on marine and terrestrial climates and climate variability for a time interval during the Pliocene, about three million years ago, when the Earth was substantially warmer than it is today. This research is establishing a global data set for use in modeling experiments. The analyses indicate that a significant portion of high-latitude temperature changes during past climate changes are related to changes in oceanic heat transport.

\section{Solid Earth Processes}


Solid Earth research is directed toward understanding shorter time scale geological processes, such as hydrothermal circulation, which accounts for most of the heat loss from the interior of the Earth through the mid-ocean ridge system. Hydrothermal venting at mid-ocean ridges produces a wide variety of important effects in overlying water columns, including formation of turbulent, buoyant plumes, the introduction of chemicals and biota, and the modification of deep ocean circulation and mixing patterns.

Volcanic eruptions can contribute large quantities of gases and aerosols (see figure) to the Earth's atmosphere and have been linked to past climate change (see figure). The USGCRP Global Volcanism Program maintains: a database of the world's volcanoes and their known eruptions of the last 10,000 years; an archive of maps, photographs, and other historical documentation of the world's volcanoes; and a Global Volcanism Network, a network tracking and reporting current volcanic activity around the world.

Investigations of surface deposits show that sand dunes and sand sheets occur extensively on the semi-arid Great Plains. These wind generated deposits are now stable because of the presence of a sparse vegetation cover. Use of a dune mobility index, which incorporates wind strength and aridity factors, shows that increased temperature and reduced precipitation could mobilize the sand deposits throughout a significant area of the U.S. Great Plains. Research using geodetic observations has demonstrated a correlation between variations in atmospheric and oceanic circulation and variations in Earth dynamics. Systematic variations in Earth's angular momentum have been observed and correspond well with El Niñ o and La Niña events.

\section{Solar Influences}

Recent research conducted through the Solar Influences Program (SIP) suggests that the mesosphere and lower thermosphere are exceedingly sensitive to changes in greenhouse gas concentrations in the lower atmosphere - small variations in the greenhouse gas concentrations are predicted to cause large changes in the temperature of these tenuous high-altitude atmospheric regions. Unlike the lower atmosphere which is expected to warm by a few degrees Celsius, a doubling of greenhouse gas concentrations could cool the mesosphere and lower thermosphere by between 10 to $50^{\circ} \mathrm{C}$. The increase in the occurrence of arctic noctilucent clouds in the mesosphere over the last 20 years indicates that such a cooling is already taking place. The influence of solar variability on global surface temperature changes may have been significantly underestimated.

\section{Predicting Global Change}

Models of the Earth system will provide the only rigorous means for developing quantitative projections of the interactions of atmospheric composition, climate, sea level, terrestrial and marine ecosystems, agriculture, water resources, and the effects of human activities. Models and related analysis activities provide the predictive link between the physical Earth system and the human dimensions of global change, including economics, social structure and evolution, and resource use and management. Enhanced activity in global modeling activities proposed for FY 1995 will build on recent advances (see Recent Accomplishments in Integrative Modeling and Prediction of the Earth System) in process studies and observations, with the goals of enhancing forecast capabilities for seasonal to interannual climate variations and strengthening the confidence that can be placed in longer-term climate projections and insights.

\section{Earth System Modeling and Long-Term Prediction}

Prediction activities contribute to the understanding of the interactions among the components of the Earth system, including: ocean circulation (see figure) and atmospheric interactions; atmospheric chemistry; potential consequences of emissions of carbon dioxide and other greenhouse gases on climate (see figure) and of chlorofluorocarbons and other gases that perturb the stratospheric ozone layer; changes in land use that 
alter water and biogeochemical balances; changes in biological systems on land and in the oceans; changes in sea level; and changes in how societal systems interact with the climate. Results from model simulations form the basis for the state-of-the- science assessments being conducted both nationally and internationally.

Research on the sensitivity and response of the Earth's climate to natural and human-induced perturbations to the radiation balance, including the effects on the climate due to changes in greenhouse gas concentrations, aerosol loading, and other factors will be conducted to support the 1994 and 1995 IPCC assessments. Researchers will use specific scenarios developed with global models to conduct comparison and evaluation studies of global change projections. Additional modeling studies will include: the climatic effects of aerosols, smoke and clouds; interannual variations in global and tropical water cycle; land use change and deforestation; and variations in atmospheric chemistry due to human activities, volcanic activity, and natural biogeochemical cycles. Results from model simulations are being compared with historical data sets to determine the extent of climate variability that can be explained by the models and their representation of the Earth system.

Accurate predictions of future global change depend on how well models can simulate the many components of the Earth system, including the oceans, atmosphere, land, and biosphere. Global and regional modeling programs are intensifying their efforts to include vegetation, biological productivity, soil processes, trace gas exchange, hydrology, atmospheric circulation and chemistry, radiation budgets, and ocean circulation. Research programs including the international Global Energy and Water Experiment (GEWEX) will provide the basis for these efforts to relate regional-scale to global-scale patterns and variables (especially precipitation, temperature, and surface roughness) that strongly influence land surface processes and their interactions with the atmosphere.

The Computer Hardware, Advanced Mathematics and Model Physics (CHAMMP) Program focuses on redesigning and rewriting models for use on the newly emerging, massively parallel computers to take advantage of their greatly increased speed and performance. CHAMMP is exploring the potential for using these new computers for century-scale climate projections and simulations and conducting analytic studies to further define the theoretical limits of climate predictability. Important improvements in the ability to run large- scale ocean and atmosphere models have been made with the continued development of high performance computers and improved algorithms and tools for model development.

Simulations from a high resolution ocean model implemented on a massively parallel computer, the first model to accurately simulate mesoscale eddies over the entire globe, compare favorably with satellite observations, demonstrating the model's ability to realistically simulate ocean circulation. The description of ocean eddies is a key factor for accurately characterizing fluctuations in the ocean circulation which contribute to climate change on the decadal and longer time scales. A version of this ocean model will be coupled to an atmospheric general circulation model for climate change research in order to contribute to the 1995 IPCC assessment.

USGCRP modeling activities will significantly augment programs that support the development of coupled models and test component models in ways that can provide deeper insights and improved projections of Earth system behavior. The USGCRP is sponsoring the development and initial testing of prototype Earth system models (ESMs) through the combined efforts of the Climate Dynamics and Experimental Prediction, Climate Modeling Analysis and Prediction, and Earth System Modeling and Global Analysis programs. These modeling efforts combine the atmosphere, oceans, land surfaces, and biogeochemistry into an adaptable and flexible system. The biogeochemical component of prototype ESMs are reproducing the seasonal variation in the atmospheric carbon dioxide record. These models are being applied to study the historical evolution of the $\mathrm{CO}_{2}$ concentration. Coupled atmosphere-ocean models are being used to investigate climate variability and climate change on time scales from seasons to centuries. Work sponsored by the USGCRP is progressing on developing realistic representations of land and natural resource interactions, vegetation, and regional land processes for inclusion in Earth system models. Detailed land surface models are being linked to coupled 
ocean-atmosphere system models, and early simulations suggest that significant relationships exist between ocean surface temperatures, atmospheric circulation patterns, and hydrologic conditions over mid-latitude continents. Sea-ice models are also being developed and incorporated into the ocean- atmosphere-land models, to yield more fully coupled climate system models.

\section{Seasonal to Interannual Forecasting}

Significant success has been demonstrated in forecasting large- scale changes in the sea surface temperature of the tropical Pacific Ocean, especially transitions into the ENSO warming events that dramatically alter precipitation patterns over much of the Pacific basin, including the southwestern United States. This improved understanding will provide both immediate and long-term benefits. On the short-term, the people and economies of the nation and world will benefit from being able to prepare for the consequences of the large natural climate fluctuations caused by ENSO events; on the longer-term, there will be better understanding of whether human activities could affect these fluctuations, which are the largest precipitation anomalies now affecting international agriculture and other human activities.

In FY 1995, the development, testing, improvement, and implementation of a quasi-operational experimental forecasting system on seasonal to interannual time scales will be extended through the establishment of a multinational network of centers to produce and distribute forecast guidance products. Activities sponsored through this network will include transfer of the products of predictive models to regional application centers around the world so that tailored regional predictions can be provided. Application of regional forecasts on time scales of interest to society are expected to aid in advance planning for agricultural production, resource use, and other societal activities.

\section{Attribution and Reconciliation with Observations}

The world is projected to warm a few degrees (Celsius) over the next century due to the increase in the concentrations of greenhouse gases. Such an increase would be about half of the rise that has taken the Earth from the glacial climate of 20,000 years ago to the warmth of the present. Some studies suggest that the effects on society and the natural environment may be very large and would require significant resources and lifestyle changes to prevent or ameliorate. It is therefore essential to understand the degree of confidence that can be placed in the model results. Models and observations are being tested and compared for a range of time periods. Such comparisons will provide a measure of the accuracy of model representations and an estimate of the confidence of model predictions.

The Atmospheric Model Intercomparison Project (AMIP), which contributes to the WCRP's CLIVAR program, is diagnosing the abilities of global atmospheric models to represent the present climatic state and the observed climatic variations over the recent past, specifically 1979 to 1988. About 30 modeling groups from around the world are carrying out test simulations. The set of runs will be completed in 1994 and the analysis of the runs in 1995. Disagreements with observations and with other models, including regional temperature biases, excessive precipitation, and abnormally strong winds, are being examined. Once this part of AMIP is completed, the focus will shift to examining the capabilities of ocean- atmosphere models to simulate climate variations and change.

To provide more complete data sets for continuing research on model fidelity, four-dimensional data assimilation techniques are being developed and used to combine many kinds of satellite and surface observations to produce carefully checked data products for research, monitoring, and applications. A prototype model-driven data assimilation system has been developed and used to produce a set of reanalyzed data fields for 1985-1989. These data will be used to study and test model simulations of the 1986-87 El Niñ o (warm event) and the La Niñ a (cold event) of 1988. 
Model simulations of paleoclimatic changes are also underway to understand the ability of models to predict very long term climatic change and to understand the sensitivity of climate to past changes in atmospheric composition and radiative forcing [see earlier subsection on Earth system history]. These simulations and related analyses suggest that the modeled estimates of climate change are roughly correct, although problems in understanding the reasons for past climate changes limit the accuracy of the simulations that can be performed.

Of most importance, but hardest to accomplish, is to test model performance against the observed climatic changes of the past two hundred years. This is due in part to there being multiple influences that affect the climate, including: (1) human-induced changes in greenhouse gas concentrations, in ozone concentrations, in the atmospheric loading of sulfate, and biomass aerosols; and (2) natural induced changes in volcanic aerosol loading, in solar irradiance, and, possibly, in ocean circulation. It is especially difficult to construct a model test that can consider all of these factors together for comparison to the changing set of conditions since the start of the Industrial Revolution. The USGCRP agencies are engaged in a continuing effort to formulate an effective approach for carrying out such an analysis.

\section{Evaluating The Consequences}

Evaluating the consequences of global change includes determining and interpreting the environmental and societal impacts of global change, and understanding the potential for adaptation and mitigation to ameliorate adverse impacts (see Recent Accomplishments in Evaluating the Consequences of Global Change).

\section{Environmental Impacts and Adaptation Mechanisms}

The FY 1995 Program proposes to enhance research to improve fundamental understanding of physiological and ecological responses of plants and animals to global changes of climate, atmospheric gas concentrations, and increased UV-B radiation. The international Global Ocean Ecosystems Dynamics (GLOBEC) program examines the relationship between physical and biological oceanic processes that govern how the recruitment of marine fishes and zooplankton are linked to climatic change. Sensitivity analyses are being conducted to determine the effects of UV radiation on the oceanic carbon cycle in relation to global warming.

Methodologies are being developed and validated for estimating the effects of global climate change on lake environmental conditions and fishery resources at a regional scale. The reproductive dynamics of fishery resources, such as sardine, anchovy, and mackerel stocks off the coasts of California, Chile, Spain, and West Africa are being examined.

New research will be initiated to further evaluate the potential impacts of climate change at the regional level (see figure). Recent modeling studies have successfully simulated winter precipitation at the local scale for a high-elevation, high-water-yielding mountain watershed in western Colorado by coupling regional/local scale atmospheric models to watershed models. These models helped investigate the effects of possible increases in temperature at Federally-managed reservoirs in western watersheds that might result from a doubling of atmospheric $\mathrm{CO}_{2}$. The results indicated that the effects of the temperature increases on aquatic ecosystems and fisheries could be significant.

Research on the global and regional effects of climate change on agriculture has shown that, for a moderate scenario of climate change accompanying a doubling of greenhouse gases, the production potential of global agriculture may not be seriously threatened. These results are sensitive to the positive direct effect of carbon dioxide fertilization on plant growth. These results also suggest agricultural production losses may be more severe in developing countries. Additional research in this area is proposed for FY 1995.

Studies are currently underway to determine how atmospheric deposition affects tree growth. The interactions of deposited pollutants with global change parameters (e.g., elevated $\mathrm{CO}_{2}$ ) and with biotic stresses (e.g., 
insect feeding) are also being investigated. These studies have demonstrated that pollutants such as ozone and elevated $\mathrm{CO}_{2}$ influence insect behavior, and hence forest health. New research is proposed to refine ecosystem response models and improve the ability to anticipate ecosystem fluctuations due to climate change.

Contributing research on the adaptation of natural ecosystems to global change includes forest health monitoring, studies on threatened, endangered, and sensitive species, and research into the physiological basis of resistance to drought, ultraviolet radiation, and other stresses for developing crop cultivars that can withstand climate change better than current cultivars. Modeling of the economic impact of climate change scenarios on forest inventories in the southern U.S. is also in progress.

Global change, particularly changes in land use, can have substantial impacts on the preservation of species diversity. Landsat images of Brazil, for example, have shown a large increase in the fragmentation of the habitat, a process that could reduce the number of plant and animal species (biodiversity). The area shown to be severely fragmented, and hence with potentially diminished biodiversity, was more than twice the area actually deforested.

\section{Societal Impacts and Adaptation}

Various sectoral analyses are planned to evaluate the consequences of climate change on human society. To meet the commitments of the President's Climate Change Action Plan, there is a need for increased understanding of the ability for communities to adapt to a warmer climate and to new policies that may be imposed to address the climate change issue. Research on how consumption patterns may change with a warming climate is necessary in developing response options. For example, options for responding to possible increases in average temperatures due to greenhouse warming must contrast the reduced demand for spaceheating with the increased demand for space-cooling.

Uncertainty about the adaptability of societies to global change is due in part to uncertainty about future technological change. How will industrial development, future industrial and consumer products, and technological improvements change polluting emissions, help abatement of, and lead to adaptation to environmental changes? How will the supply and demand for goods and services change? Answers to these questions have implications both for predicting future global change and for evaluating the effectiveness of national and international government policies to reduce the impacts of change. Technological innovations and changing production patterns could greatly ameliorate or exacerbate both abatement and adaptation. Research on the innovation process and the subsequent diffusion of new technologies and products will be expanded to address these issues.

Significant research is being conducted to provide information about the health effects on humans of increased UV radiation and CFC substitutes. Health studies on the effects of increased UV exposure focus on the impacts on the immune system, aging process, sensitive tissues, and methods to reduce these harmful effects. The principal objectives of these studies are to promote an increased understanding of UV effects on target organs (e.g., eyes and skin) and the molecular changes that lead to these effects, and to help develop strategies to prevent the initiation of disease or to intervene before disease.

Animal models indicate that exposure to environmentally relevant doses of UV-B radiation can adversely affect the course of certain infectious diseases. Tests show that exposure to UV-B can drastically reduce survival time after exposure to lethal agents. Other research has shown that the ability of UV radiation to impair the development of cell-mediated immunity depends on the particular antigen administered, and that DNA is the primary target of UV radiation in the generation of systemic immunosuppression.

The global implications associated with seasonal to interannual variations in the climate include potential shifts in the patterns of drought, flooding, and severe storms. These events can have unfortunate social and 
economic consequences in developed countries, and often have disastrous consequences in developing countries with economies that are largely dependent upon their agricultural sectors as a major source of food, employment, and foreign exchange. Experimental predictions from ENSO models can be used to provide advance warning to decision makers, which allows them to adjust the type and timing of crop planting in anticipation of anomalous climate patterns associated with ENSO events.

\section{Mitigation Strategies}

Mitigation strategy research within the focused USGCRP includes: evaluation of CFC substitutes and the environmental implications of the proposed substitutes and their degradation products; the development of models for predicting responses of major agricultural crops to climate change and the development of management tools for ameliorating undesirable effects; and studies on reforestation of presently deforested areas in the tropics.

Research on replacements for chlorofluorocarbons (CFCs) is focused on understanding potential impacts on humans and the environment. Because the toxicity of many compounds is associated with their metabolism, the metabolism and toxicity of hydrochlorofluorocarbons (HCFCs) and hydrofluorocarbons (HFCs), known collectively as $\mathrm{H}(\mathrm{C}) \mathrm{FCs}$, are being investigated. The available data indicate that compounds that are rapidly metabolized are more toxic than those that are slowly metabolized. For example, HCFC- 132b is very rapidly metabolized and yields metabolites that are very potent inhibitors of the enzymes used by the body to detoxify many drugs and chemicals. As a result, its development has been discontinued. Other research shows that the possibility exists that HCFC-123 may increase susceptibility to hepatitis in sensitive individuals. Finally, computer modeling studies of reactions of $\mathrm{H}(\mathrm{C}) \mathrm{FCs}$ are being conducted. The objective is to develop models that will allow prediction of the rates of metabolism of $\mathrm{H}(\mathrm{C}) \mathrm{FCs}$ and identification of $\mathrm{H}(\mathrm{C}) \mathrm{FCs}$ that are likely to be poorly metabolized and, therefore, have little toxic potential. Preliminary results of this research have been very promising, and the range of compounds to be tested has been expanded.

The biospheric transport and fate of CFC substitutes are also being investigated in order to assess likely future concentrations of these new chemicals in air, water bodies, and soils. Models are being developed to predict the potential ecological impacts of the substituted chemicals and their degradation products.

To ensure a continued abundant supply of food and fiber, research is being conducted on management tools for responding to the potentially undesirable effects of climate change on agricultural productivity. This research involves the development of methods for aggregating plant-scale models to make predictions of impacts at regional scales. Improved predictions of the response of terrestrial ecosystems to changes in temperature, rainfall, solar radiation, especially UV radiation, and changes in carbon dioxide concentrations will enable the development of management strategies for mitigating the adverse impacts caused by these changes.

A pilot project is underway in a tropical area severely affected by deforestation and consequent erosion to study the restoration of the fertility of degraded soils and the improvement of forest cover. The system combines small-scale tree farming, horticulture, fodder production, and animal husbandry. Future plans include the expansion of the area to explore economies of scale, and to test new tree and crop species.

A very substantial amount of climate change mitigation research is being conducted outside of the focused USGCRP. The Mitigation and Adaptation Directory, compiled by the CENR Subcommittee on Engineering and Technology Research, reported that approximately \$25 million was spent on focused mitigation and adaptation research in FY 1993 and \$78 million will be spent in FY 1994. In FY 1993, about \$1 billion was spent in research contributing (but not necessarily targeted specifically for mitigation) to the development of mitigation technologies and \$1.5 billion is planned for FY 1994. The proposed FY 1995 budget includes about $\$ 1.5$ billion in contributing research on mitigation and adaptation. As described earlier in this document, about 
\$280 million of specifically identified activities (not part of the USGCRP budget) are planned in FY 1995 associated with the commitments to reduce greenhouse gases as part of the Climate Change Action Plan.

There is over a half billion dollars of contributing funding, outside of the USGCRP focused program, proposed for greenhouse gas mitigation-related research in FY 1995. This includes: the development of more efficient combustion systems which include clean coal technologies, advanced turbine systems for natural gas, and fuel cell systems which operate on natural gas and coal based fuels; alternative energy research, including wind, solar, geothermal and photovoltaics; research on alternative vehicles and fuels, advanced materials research for new transportation technologies; research to develop more energy-efficient appliances, space heating and cooling equipment, and energy-efficient buildings; research on improving the efficiency of electricity transmission, storage, and distribution reducing the need for new production facilities; and research on reducing greenhouse gas emissions and developing more energy-efficient processes for the chemical, petroleum refining, paper, textiles, food processing, and other manufacturing industries.

\section{DEVELOPING TOOLS FOR ASSESSING POLICIES AND OPTIONS}

The USGCRP plans to expand its support of research designed to advance knowledge of the ways that human activities affect natural systems and the global environment. More support also will be given to research on the ways that changing environmental conditions affect humans and the many activities in which they engage. Just as humans influence global change through their activities, individuals and organizations can influence global change by making decisions that would enable them to reduce adverse impacts on the environment and to adapt more successfully to changing environmental conditions. The USGCRP will increase emphasis in FY 1995 on developing tools for assessing policies and options for dealing with global change (see Accomplishments in Developing Tools for Assessing Global Change Policies and Options).

A new emphasis will be placed on the examination of policies in innovative modeling frameworks to identify options that are available for responding to global change, and to analyze the relative strengths and weaknesses of those options. In order to be of more assistance to governments, USGCRP results need to be better communicated in a way that contributes directly to the formulation of domestic policy and to the development of international protocols and conventions. Enhanced research on assessing policies and options, therefore, will involve leading social, economic, and policy scientists, whose expertise is necessary to understand the dynamics and interactions of human activities with global change, and whose collaboration with natural scientists and engineers is required to develop effectively integrated tools and models. Such collaboration is essential for addressing issues such as predicting the diffusion of new energy-conserving technologies, refining feedbacks within general circulation models that link human-generated emissions with climate, and identifying management strategies that can help preserve natural resources and biodiversity.

In addition to conducting fundamental research on processes through which governments and other human institutions examine policies and options, the USGCRP will promote development of new analytic and decision-making tools and the collection of critical information needed in policy- and decision-making processes. Furthermore, the USGCRP will foster more thorough evaluation of adaptation and mitigation technologies. Most importantly, the USGCRP plans to accelerate the development of methods for conducting integrated assessments, and assist in the conduct of some focused national and international assessments on differing time and spatial scales.

The USGCRP's special emphasis on assessing policies and options in FY 1995 is based on improved communication among researchers and policy makers. New forms of cooperation, such as innovative partnerships among researchers and policy makers in different Federal agencies as well as in academia and the private sector, will be expanded and enhanced. To facilitate cooperative work, funding cycles and 
proposal reviews across agencies will be coordinated more closely.

\section{Social, Economic, and Policy Science Research}

A major part of the USGCRP's expanded research effort in FY 1995 will consist of increased research in the social, economic, and policy sciences. Among the most important uncertainties that researchers need to address are the processes through which people become aware of changes in environmental conditions and the ways that they change their behavior in response to those changes through voluntary and coordinated actions. While some effort will be focused on the dynamics of individual decision making, more emphasis will be given to exploring the ways that responses to environmental change are channeled through economic, political, and legal systems as well as through informal organizational structures.

Better knowledge of human-environmental interactions over longer time periods is needed. Many economic models, for example, rely on information gathered by observing the behavior of individuals or groups under specific circumstances. These perspectives are valuable, but they need to be augmented with understanding derived from longer-term anthropological, geographic, and sociological perspectives in order to more fully appreciate the implications of global change on people during the coming decades. Similarly, the changing nature of political institutions and protocols for developing international agreements may differ significantly in the future.

Special emphasis in the USGCRP during FY 1995 will be given to exploration of the processes through which policies are developed, implemented, and evaluated. Policy science research will examine the ways through which policy questions are framed, including the procedures through which the values of different resources and conditions are established. Different disciplines employ different methods for assigning values, and comparison of these approaches is necessary to determine how the concerns of different stakeholders may be reconciled. Attention also will be given to procedures through which different governments or other kinds of organizations work together to achieve common objectives. Through such research, policy science can provide insights into new approaches that may achieve a more lasting consensus.

Policy science research also will focus on the data, analytic, modeling, and computational needs of policy analysts. The appropriate elicitation and utilization of expert judgments to help fill crucial information gaps will be evaluated. Analytic approaches to be explored include the extraction of general information from case studies, identification of mechanisms for estimating parameters in models, and evaluation of the degree to which assumptions have been maintained in the development and validation of models.

\section{Integrated Assessment Capabilities}

The FY 1995 USGCRP budget proposes a marked increase in its support of activities to improve integrated assessment capabilities. These activities will support the policy process by bringing scientific research results into frameworks that are useful to national and international decision makers. The integrated frameworks will also identify priorities for natural and social science research programs by highlighting critical gaps in knowledge. Once they have been developed, integrated assessment procedures will help policy makers to carefully evaluate the potential implications of different options. For example, not only will decision makers be able to evaluate the direct and indirect impacts of new technologies on future greenhouse gas emissions, they also will be able to assess how different policies are likely to affect the rates at which new technologies are adopted.

Improvements in integrated assessment capabilities require investments in both integrated models and in the research that provides the foundation on which models are based. Integrated models that can be used to conduct comprehensive assessments and evaluate policies and other options require adaptation of reducedform models, which are already under development for many natural systems. They also will require 
development of accounting mechanisms that will enable non-monetary factors to be included. New insights into integrated assessment modeling are resulting from evaluating modeling approaches that have already been developed and tested.

Some of the research to advance integrated assessment modeling capabilities will occur inside the Federal agencies, but most will be undertaken in academic and private-sector organizations. In addition to advancing methodological capabilities, case studies of their effectiveness will be undertaken. The impact of the Administration's Climate Change Action Plan for mitigating greenhouse gas emissions will be evaluated in order to provide a foundation for subsequent actions. Benefit-cost analyses will also be conducted of recommendations in Policy Implications of Greenhouse Warming, a 1991 study of the National Academy of Sciences undertaken in response to a provision of the Energy Policy Act.

The potential utility of integrated assessments already has been demonstrated through research on different strategies to reduce greenhouse gas emissions. A comparison of several models indicates that the use of carbon taxes to stabilize carbon dioxide emissions at current levels (by the year 2000) could result in costs of between $0.1 \%$ and $0.5 \%$ of the gross domestic product (GDP). The same models predict that a reduction of $20 \%$ in carbon dioxide emissions by 2010 could have associated costs of from $1.0 \%$ to $1.7 \%$ of the GDP. However, these models do not include the consideration of options such as the use of trees to sequester carbon. Research has shown that forestry options that encourage tree planting, although perhaps limited in scope, have costs that compare favorably with actions such as energy conservation and conversions to less carbon-intensive fuels. These models also assume that the revenues from the carbon taxes are redistributed in a neutral manner. However, recent research has shown that revenues from carbon taxes can be "recycled" in ways that can decrease GDP costs by offsetting other taxes. Finally, these analyses did not consider the recognized potential for improved market performance to provide emissions reductions at lower or possibly negative costs. Further research on these models is proposed for FY 1995.

\section{Decision Tools and Information}

An important area of USGCRP emphasis in FY 1995 will be the continued development of decision tools and analytic approaches to assist both short- and long-term needs of decision makers. In recognition of the fact that many responses to global change must be made at regional to national levels, many of these tools need to be local in character. Because of their sharply defined focus, these tools can be developed, tested, and disseminated quickly. As a result, many new decision tools can be directly employed to address specific problems while subsequent research assesses the degree to which they can be adapted for broader purposes. These new tools will enable national and international decision makers to address competing objectives and to analyze potential trade-offs among available options. There is particularly high demand for new decision tools that can be used in coastal zone management. Management of fisheries, flooding, erosion, water quality and allocation, and sea-level rise in coastal settings requires the development of adaptive strategies.

Recent successes in the refinement of decision-support tools have been possible through advances in knowledge of critical natural processes. As understanding of the frequency and scale of physical phenomena has increased, decision tools have been refined to reduce uncertainties about the socioeconomic consequences of environmental changes. One example is the improved predictive accuracy of the onset of an ENSO event. Using more accurate forecasts, resource managers have been able to alter management strategies for water use and agricultural practices to reduce economic impacts.

Another example of the value of improved decision tools is the incorporation of site-specific scientific information into economic models. Using new methods, regional distributions of environmental risks can be mapped more accurately, thereby assisting in urban planning and selecting locations for new transportation corridors and industrial facilities. Probability models are examples of successful decision tools which can, as an example, estimate the human impacts of severe rainstorms that reduce the stability of hillslopes. These 
models demonstrate how site-specific data applied in a regional context can assist emergency-response managers in prioritizing locations for evacuations when rainstorms become severe.

\section{Resource Use and Management Tools}

An important area of research in FY 1995 will be on resource use and management related to global change. This line of research directly supports the pursuit of sustainability. Resource issues are location and scale dependent, and numerous advances have been made in knowledge of the ways that resources are used and managed in local and regional settings. Many advances have resulted from more sophisticated use of remotely-sensed data (see figure). Important improvements have been made in the interpretation of satellite imagery for different areas where tropical rainforests abound, for example. When coupled with field-based studies of land-use and forest-regeneration processes, more complete understanding has been achieved of the successive stages of vegetation on sites where trees have been cleared or on which biomass burning has occurred. This research has shed light on natural, demographic, economic, and social factors that result in much more rapid regeneration in some locales than in others. This kind of knowledge is useful for designing more effective land use policies.

Go to Chapter 4

Return to Chapter 2

Return to Table of Contents 


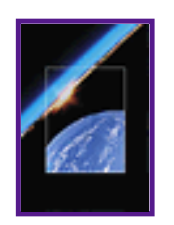

\section{Our Changing Planet FY 1995}

\section{Linking To The International Community}

The USGCRP is founded on the premise that international cooperation and coordination are fundamental to addressing global environmental issues, and USGCRP programs contribute significantly to world-wide global change research efforts (see figure).

\section{INTERNATIONAL ASSESSMENTS}

The U.S. is a major participant in international efforts to understand and assess the state of knowledge about global change issues. Hundreds of scientists from more than fifty countries have participated in the recent Intergovernmental Panel on Climate Change (IPCC) science assessments and the World Meteorological Organization (WMO)/ United Nations Environment Programme (UNEP) assessments of ozone, which Have included review of scientific results, environmental impacts, technologies, and economic considerations. Intergovernmental assessments are intended to serve as primary inputs to many international conventions and protocols that the U.S. supports, including the Framework Convention on Climate Change (FCCC), the Montreal Protocol on Ozone, and the Convention on Biological Diversity.

The IPCC was established by the WMO and UNEP in 1988. It derives part of its mandate from the UN General Assembly. The purpose of the IPCC is to lead the assessments on the climate change issue. These assessments over the past five years have not only provided information requested by governments, but also have served to identify components of the climate change issue that deserve priority attention from the research community. To date, the IPCC has produced the 1990 Assessment Report and a 1992 Supplement. Together, these reports establish a common basis of scientific knowledge. This science base has been used by governments in negotiating the Framework Convention on Climate Change, which was signed at the U.N. Conference on Environment and Development (UNCED). A Second Supplementary Report to the IPCC Scientific Assessment, focusing on radiative forcing of the climate system, is scheduled for release in June 1994 and will serve as the scientific input to the First Meeting of the Parties of the FCCC, currently anticipated to be held in 1995.

IPCC is also due to complete a second comprehensive assessment in 1995. Member agencies of the USGCRP will continue to closely coordinate efforts to assure support for participation of U.S. scientists in the three IPCC working groups. Working Group I, co- chaired by the United Kingdom and Brazil, is charged with assessing the state of science with respect to the climate system, including possible changes to it resulting from human activities. Working Group II, co-chaired by the United States and Zimbabwe, assesses potential impacts, adaptation, and mitigation measures. Working Group III, co-chaired by Canada and South Korea, addresses cross- cutting issues, including the economic implications of climate change and of selected emissions scenarios.

Participation of U.S. scientists as lead and contributing authors is particularly strong due to the many activities supported by the USGCRP. In addition, the USGCRP has established an IPCC Secretariat for Working Group 
II. The Secretariat provides international and U.S. coordination, as well as support to U.S. authors of the 1994 supplement and the 1995 IPCC assessments.

U.S. scientists, with strong support from the USGCRP, have also played a leadership role in developing a series of international assessments of stratospheric ozone depletion. In accordance with the provisions of the Montreal Protocol on Substances that Deplete the Ozone Layer, which entered into force in January 1989, UNEP, in coordination with WMO, has sponsored a series of reports assessing the current state of knowledge of (1) scientific, (2) environmental, and (3) economic and technological matters relevant to implementation of the Protocol. The assessments are prepared at least every fourth year at the request of the Parties.

The UNEP/WMO assessments serve as the internationally recognized technical input underlying decisions taken by the Parties to amend the Protocol. The 1989 assessments were used as the basis for the London Amendments adopted in 1990, and the 1991 assessments were used as the basis for the Copenhagen Amendments adopted in 1992. A 1992 supplementary assessment on the science, technology and economics of methyl bromide served as the basis for decisions made that year by the Parties to limit methyl bromide use. Current plans call for a 1994 set of assessments for consideration at the Seventh Meeting of the Parties in 1995.

\section{INTERNATIONAL RESEARCH PROGRAMS}

The USGCRP is a major contributor to international global change research programs. Many nations, both developed and developing, contribute to this international cooperative research, primarily through three major international programs: (i) the World Climate Research Programme (WCRP); (ii) the International Geosphere- Biosphere Programme (IGBP); and, (iii) the Human Dimensions (of Global Environmental Change) Programme (HDP).

International programs are coordinated at a series of levels, including scientist-to-scientist, agency-to-agency, and government- to-government through a broad range of multilateral and bilateral organizations and arrangements (see figure). Many of these arrangements involve United Nations agencies concerned with global change research, including WMO, UNEP, and the Intergovernmental Oceanographic Commission (IOC) of UNESCO. The International Council of Scientific Unions (ICSU) provides strong leadership for scientific planning for many of these key international programs, especially the WCRP and the IGBP. The U.S. shares in funding ICSU's coordination of these activities, and U.S. scientists and agencies participate on and interact regularly with ICSU, its Secretariat, and various related committees. U.S. scientists have chaired many of the international scientific steering groups for the major international global change research programs. Moreover, the USGCRP supports the international offices of the IGBP Task Force on Global Analysis, Interpretation, and Modeling (GAIM) located at the University of New Hampshire and the IGBP regional field programs as well.

Some examples of global change research activities on the regional level include the sponsorship in 1994 by the North Pacific Marine Science Organization (PICES) of workshops on Monitoring Subarctic Pacific Ocean Variables and on developing a PICES-GLOBEC International Program on Climate Change and Carrying Capacity. In addition, a new PICES Working Group will begin addressing important questions on modeling of the subarctic North Pacific circulation. In August 1993 the International Council for the Exploration of the Sea (ICES) sponsored a symposium of GLOBEC scientists on Cod and Climate Change in the North Atlantic. An ICES Working Group will convene ICES-GLOBEC workshops in 1994 to assist in distinguishing anthropogenic from natural changes affecting cod stocks.

Leading international economic organizations are also now considering how global change might impact economic development and are identifying global change research-related issues. These include the Organization for Economic Cooperation and Development (OECD), which in 1993 convened an experts' 
meeting on global change that recommended greater scientific input from the social science community to the policy process, and the Asia-Pacific Economic Cooperation organization (APEC), which is reviewing the impacts and effects of global change in the Asia/Pacific region in its Marine Resource Conservation Working Group.

\section{INTERNATIONAL INSTITUTES/NETWORKS}

The U.S. is currently placing special emphasis on the development of networks and institutes to promote the development of regional capabilities to conduct global change research. The agreement establishing the InterAmerican Institute for Global Change Research (IAI) is expected to enter into force early in 1994, following ratification of the agreement in 1993 by the requisite number of signatories. The IAI Conference of the Parties is expected to meet for the first time in the spring of 1994. The United States will be working closely with the other Parties to assure that the Conference adopts a broad regional scientific program that also contributes to global objectives. The U.S. will continue to support scientific workshops, which are needed to provide a basis for the IAI's scientific program.

The U.S. expects to work closely with the European Union and the countries of Central and Eastern Europe and of Africa to develop regional global change research agendas for the European Network for Research in Global Change (ENRICH). ENRICH is intended to improve coordination of global change research in three areas: Western Europe; Central and Eastern Europe; and Africa. The European Union is expected to soon establish a central ENRICH Office in Brussels with liaison offices in each of the above three regions.

Japan hosted, in January of 1994, a second workshop to plan an Asia-Pacific Network for Global Change Research (APN). This workshop advanced planning for an APN to serve as a framework within which sub-regional networks, in areas such as southeast and temperate East Asia, can coordinate their research efforts. It is expected that the APN will focus on issues of regional scope, such as tropical and coastal processes in the Pacific.

The U.S. will continue to actively support establishment of a multinational network of centers to develop and issue experimental seasonal to interannual climate predictions. The purpose of this network is to improve understanding of the global climate system, to advance our ability to predict ENSO-related climate variability on seasonal to interannual time scales, and to produce and systematically disseminate regionally-tailored climate forecasts for use in a wide range of economic and social planning activities. Activities in 1994 include: the convening of the second in a series of nine-month training exercises for international climatologists at the Lamont-Doherty Earth Observatory; workshops to examine the potential applications of climate predictions for North America and Africa; application exercises in Peru, the Pacific islands, Brazil, Australia, Southeast Asia, and southern South America; and a high-level intergovernmental meeting to launch multinational coordination of those activities.

The international commitment to build indigenous capacities for global change research in the developing world is reflected in the SysTem for Analysis, Research and Training (START), a joint effort of the HDP, IGBP, and WCRP to develop regional research networks for global change. The START regional research networks promote focused research and training on regional issues of global importance, integrate and synthesize the research results, and provide input to decision makers at national and regional levels. The USGCRP supports the operation of the START Secretariat and the participation of U.S. scientists in the development of the START scientific agenda.

\section{INFORMAL INTERNATIONAL COORDINATION GROUPS}

Just as U.S. scientists interact with their counterparts in other countries, U.S. science agencies also work with 
their counterparts through informal international coordination groups, such as the International Group of Funding Agencies for Global Change Research (IGFA) and the Committee on Earth Observation Satellites (CEOS). IGFA met in January 1994 to discuss ways to expand the participation of developing countries in global change research through improving their national funding processes to support increased research on global change. IGFA also sponsored a separate meeting of IGBP and HDP donors which was intended to assure effective, shared, international support for the centralized operations of the IGBP and HDP, especially their international offices and secretariats. In October, IGFA will review progress in development of socioeconomic research on global change, in particular through the HDP, and focus on the role of national funding agencies in supporting such research.

CEOS is focusing over the coming year on three major topics. The first involves establishment of networks for global satellite observational data, which includes consideration of surface networks as well. CEOS has set up an ad hoc working group on this issue, which will include U.S. scientists and is expected to be very active in 1994. CEOS provides a forum for promoting the full and open exchange of data at minimal cost (a policy the U.S. strongly endorses). Pilot projects with IGBP involving access to high resolution satellite data at substantially reduced prices are underway. CEOS will also address data exchange principles for noncommercial operational, environmental uses that benefit the public. U.S., European, and Japanese science agencies are planning an international workshop in April, 1994 to address this issue.

A May 1994 workshop, to be hosted by the Federal Republic of Germany, will provide an opportunity for international organizations affiliated with CEOS to continue refining and prioritizing their observational requirements from space and for CEOS members to evaluate the capabilities of current and planned satellite systems to meet those requirements. Another CEOS workshop will be hosted by Brazil in May 1994 to consider how CEOS members might encourage the use of Earth observation data in developing countries. The tenth anniversary of CEOS will be marked in the coming year to bring increased international recognition to this informal organization, which has contributed significantly to global change research through improved coordination among Earth-observing satellite operators in payload planning, calibration and validation, networking, data management, and data policy.

\section{BILATERAL AND MULTILATERAL COOPERATION}

The United States participates in a wide range of bilateral science and technology agreements and less formal arrangements. These activities support the specific scientific interests of the U.S. and the other parties, and may also support global change research activities, directly or indirectly.

Bilateral agreements with Japan, involving global change research, include the U.S./Japan Science and Technology Agreement (UJST) and the U.S./Japan Natural Resources Agreement (UJNR). Moreover, U.S. cooperation with Japan includes global change data and information exchange and cooperative space missions for Earth observation. More than 47 global change projects are ongoing with Japan through the UJST, including a series of workshops to identify topics for and to promote cooperation between Japanese and U.S. scientists. A third workshop, planned for late 1994, will consider how scientists in both countries might best improve capabilities in modeling the impacts of global change. The U.S. and Japan also recently sponsored a workshop under the UJST on Applications of Remote Sensing Technology to Natural Disaster Reduction. This workshop identified specific projects for bilateral cooperation, including data exchanges for disaster warning and mitigation.

Another activity between the U.S. and Japan is the Global Observation Information Network (GOIN) initiative, carried out under the U.S.-Japan Common Agenda for Cooperation in Global Perspective. The GOIN Joint Working Group, which met twice during 1993, identified existing and planned networks, proposed candidate data sets and prototype demonstrations, and drafted a two-year work plan. 
A bilateral agreement with Russia supporting joint research on environmental change has been in place for 22 years. Several dozen activities related to global change are underway. For example, U.S. and Russian scientists are using paleoclimatic data (especially from the large land areas of the two countries) to attempt to determine how the Earth's climate has been affected by past changes in atmospheric composition, solar insolation, and other naturally changing factors. A study is also underway of the Lake Baikal region directed toward protecting the lake's biodiversity, ensuring its sustainable use, and developing sound scientific input to land and water management plans. Research is being conducted to compare the native fish species and the effects of exotic invaders on the large fresh water systems of Lake Baikal and the U.S. Great Lakes.

The U.S. provides substantial bilateral assistance to developing countries for programs associated with issues such as climate change, biodiversity, tropical forests, water resources, environmentally sound energy use, and sustainable agriculture. Participation in international research and activities to promote the use of natural gas and clean coal technology contributes to the reduction of greenhouse gas emissions and will be particularly important given the prospects for increased use of coal in developing countries.

Arrangements have also been developed between the U.S. and other countries to support joint research. Examples include:

Indonesia The USGCRP is working closely with the Indonesian National Institute of Aeronautics and Space (LAPAN) to study the throughflow from the Pacific to the Indian Ocean, a process which is poorly understood but is a critical factor in global ocean circulation. Complementary studies of coastal and terrestrial ecology and their responses to global change are also proposed with the Indonesian Ministry for Science and Technology (LIPI).

Central and Eastern Europe The USGCRP is working with several Baltic countries to set up joint environmental monitoring and assessment programs for Baltic wetlands and terrestrial and surface water ecosystems.

The Arctic The U.S. participates in the Arctic Monitoring and Assessment Programme (AMAP), under the Arctic Environmental Protection Strategy, which is developing a computer inventory of pollutants that affect the region. The USGCRP, in cooperation with the Russian Academy of Sciences, is supporting an analysis of the biospheric role of the Siberian forests and their influence on global change.

Brazil The U.S. also participates in the Brazilian Rain Forest Pilot Project, initiated by the Government of Brazil in cooperation with the G-7 countries at the 1990 Houston Economic Summit. This project is intended to improve the knowledge and understanding of Amazonian ecosystems, promote sustainable natural resource management, and encourage the application of environmentally friendly technologies to improve human conditions in the region.

Country Studies The United States has initiated a \$25 million program (\$18 million funded by the USGCRP) to assist developing countries and countries with economies in transition to generate inventories of greenhouse gases, assess their vulnerability to climate change, and evaluate strategies for reducing net emissions of greenhouse gases and adapting to potential impacts of climate change.

The Country Studies initiative complements the President's commitment to reduce U.S. greenhouse gas emissions to 1990 levels by the year 2000 and reaffirms the U.S. commitment to the objectives and principles outlined in the Framework Convention on Climate Change.

$\underline{\text { Go to Chapter } 5}$

$\underline{\text { Return to Chapter } 3}$ 


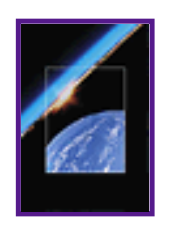

\section{Our Changing Planet FY 1995}

\section{Global Change Education And Public Awareness}

Recent scientific findings have brought a new awareness of both natural and human-induced factors that contribute to global change as well as the realization that specific responses may be required to preserve physical, economic, and societal well-being. Selecting appropriate responses will require input from a non-homogeneous community that includes global change investigators, developers of environmental technologies, educators, international, national and regional/local policy makers, decision makers in the public and private sectors, and the general public. An effective education and communication program that addresses the information needs of and improves the dialog among a broad spectrum of constituencies must therefore be a critical element of the USGCRP (see figure).

The education and communications challenge is to develop methods and tools to achieve the following objectives:

- Involve public and institutional decision makers in program planning and examination of policies and options;

- Expand public awareness of global change, including awareness of the prominent issues, their scientific complexity, and research needed for predicting consequences and evaluating national and international policy options for responding; and

- Train future scientists, engineers, and educators by promoting understanding among educators and decision makers of the multidisciplinary nature of global change issues and solutions.

\section{IMPROVING COMMUNICATION WITH DECISION MAKERS}

The effective conduct of the USGCRP is dependent on dialog among the various constituencies of the program. The USGCRP has undertaken specific initiatives to meet this objective.

In addition to providing research information for the public and user community, the USGCRP will involve these groups in formulation of the research agenda. During 1994, as part of the triennial process to prepare the ten-year research plan, there will be outreach efforts to solicit input on what the critical research questions and needs are. Comments will be sought to help develop and refine the program plan on what information is most needed by the community in considering and preparing its response to the changing global environment. On a continuing basis, the public, the user community, and scientific researchers are invited to contact the new Office of the USGCRP to offer suggestions about the research program and, through the newly established Global Change Research Information Office, to inquire about program activities and findings.

The USGCRP is also investigating other mechanisms to improve dialog with the user community. The approaches include a combination of the traditional as well as new technologies in order to reach the broadest audience. Program announcements and results are reported in a number of publications, both general news 
and global change specific. The SGCR will establish bulletin boards to reach users of the information highway. In 1994 a pilot project will be developed to both apprise users of the status of the GCDIS and solicit comments on its implementation. The user input will be incorporated into plans for both needed data and information as well as functions for accessing these resources. This pilot project will then be expanded to provide similar services for the other SGCR components.

The private sector is a key stakeholder in global change research. In 1990, the interagency Committee on Earth and Environmental Sciences established a working group, the Private Enterprise - Government Interactions (PEGI) Working Group, to coordinate interactions between government agencies and the private sector in such research. This working group provides a focal point to encourage interactions between industry, academia, and non-profit organizations and the Federal research organizations. PEGI's membership consists of representatives from all 25 agencies involved with environmental and natural resources research.

The private sector currently conducts significant research in the areas of environmental and natural resources, some of it already in conjunction with Federal agency programs. The USGCRP encourages private sector and government agency interactions to minimize duplication, to focus on key problems and issues, and to bring working-level researchers together.

\section{EXPANDING PUBLIC AWARENESS}

The general public is the ultimate decision maker for response strategies and policies. Thus, it is critical that the USGCRP provide sufficient information to improve the public's understanding of the global change science, including consequences and implications of policy options. To respond, the USGCRP has programs for general education and dissemination of data and information.

\section{General Education Programs}

The USGCRP general education program is defined as all educational programs except the graduate and post-graduate training of future scientists. The individual agencies have long standing programs for the development of educational materials for the secondary school level. Based on this framework, the agencies have developed monographs, resource guides, curricula, and other supporting teaching materials on global change, which are distributed to science teachers nationally.

To complement the agency programs, the USGCRP has launched an interagency initiative, Project Earthlink. The mission of this initiative is to launch a long-term education effort on global environmental change by increasing the understanding of global change issues, based on IPCC and similar scientific assessments, describing the effects of human actions on the global environment, and fostering access and use of scientific data sets and information technologies for informed decision making and policy formation.

Project Earthlink is being carried out in coordination with other White House initiatives, including the President's Council on Sustainable Development, Global Learning and Observations to Benefit the Environment (GLOBE), the Committee on Education and Training, Americans Communicating Electronically, and Digital Resources for Education and Training.

Six audiences will be targeted: community leaders, informal educators, teachers, students (see figure), journalists, and the general public. Planned activities include a National Town Hall Video conference on global change issues, workshops for educators and for journalists, community demonstration projects on sustainable practices, student science fair projects on global change data collection, and use of information superhighways to access scientific data sets. A highlight of these activities will occur in conjunction with the 25th Anniversary of Earth Day in April 1995. 
Materials appropriate for different audiences will be developed, including an educator resource guide, a journalist resource guide, a data set directory, a manual on the use of information technologies, and classroom activities for students. Topics include natural variability, the greenhouse effect, sea level rise, ozone depletion, ecosystem response, health effects, and decision making under scientific uncertainties.

\section{Data and Information Dissemination}

The USGCRP data and information dissemination activities are designed to serve the full range of national and international users of data and information. USGCRP agencies recognize that users may request not only research data but also derived products such as analyses and edited data collections in association with descriptive text and graphical material. Many of these value-added products are the product of choice for the non-research community.

Individual agency programs, whose focus is supporting the data and information needs of USGCRP researchers, are also supporting outreach activities to the broad global change user community. These include published and online directories, announcements in newsletters and other publications, and training workshops for teachers and educators.

To enhance the availability of data and information to the public, the USGCRP is implementing the interagency GCDIS. Representatives of the user community have been involved in the formulation of the GCDIS Implementation Plan to ensure that the needs of the various audiences are met. The GCDIS pilot projects also stress outreach. A carbon dioxide pilot project includes a component designed for K-12 use and provides an instructional tool for identifying and accessing data, images, and text. A library pilot project will use state and local electronic networks to target educational and state/local users.

The USGCRP began operating the Global Change Research Information Office (GCRIO) in 1993 in accordance with the Global Change Research Act of 1990 (PL 101-606). The purpose of the office is to disseminate to foreign governments, businesses, and institutions, as well as to private citizens, scientific research information available in the United States that would be useful in preventing, mitigating, or adapting to the effects of global change. The GCRIO also makes available the same information to users within the United States.

The GCRIO is currently tasked to: (1) determine GCRIO-specific and related global change information holdings and dissemination methods used by various agencies and develop means for conveying that information to end-users; (2) facilitate information access by developing a capability to point to, or store, retrieve, and directly disseminate global change research information; (3) provide customer service to both technically sophisticated as well as low- technology end-users as stipulated in the legislation; and (4) evaluate the functioning and effectiveness of disseminating global change information to the end-user community.

The GCRIO has identified worldwide sources of data and information to satisfy requests about global change topics. The GCRIO provides easy to use online data and information services.

\section{Training New Scientists and Educators}

The USGCRP is a long-term, diverse, complex, and evolving undertaking. Clearly, the success in the USGCRP depends upon the cooperative and energetic leadership among the participating agencies to provide a better understanding of the issues involved. The education and communications activities are central to meeting these goals, and to building an informed public capable of participating in the necessary public dialogue toward building a sustainable future.

The individual agency research programs have historically recognized the need to strengthen the human 
resource base in science and technology and to provide the United States with highly trained and educated individuals. Thus, at the inception of the USGCRP, the agencies augmented this resource base to respond to the cross-disciplinary aspects of global change.

The major emphasis of USGCRP educational programs has been to award competitive graduate-level and postdoctoral fellowships for developing the interdisciplinary problem-solving skills that are necessary for addressing global change science, technology, and policy issues. In many global-change fellowship programs, postdoctoral and graduate-level fellows are encouraged to interact with the scientific staff of the various Federal research organizations. The postdoctoral fellows conduct research either at agency laboratories or as a part of university research projects. Graduate fellows are also being trained and educated at many different universities and are participating in USGCRP sponsored research.

Training and educating young scientists to help meet the challenges of a changing world is necessary to ensure a secure future for present and future generations. The USGCRP has set as a major goal the enhancement of knowledge about the state of and changes in the Earth-system. As an extension of that goal, the USGCRP is working to develop an informed and literate public able to utilize the results of scientific research to make wise choices for sustaining human societies and the environment.

Return to Chapter 4

Return to Table of Contents 


\section{APPENDIX A:}

\section{The Proposed USGCRP Budget for FY 1995}

For FY 1995, the President is requesting a budget of \$1.81 B for the integrated, multi-agency U.S. Global Change Research Program. This request includes \$316 M of new funding for the Program, the details of which are shown in the enclosed tables. In addition, the President's request includes \$55 M in funding for already established programs that have, as a consequence of the broader vision of global change, been recategorized into the focused part of the USGCRP.

The significant increase in funding for global change research in these stringent budgetary times is a consequence of the growing world wide recognition of the importance of global change and of the need for the United States to be one of the leaders in addressing the many aspects of this issue. In preparing this budget, the USGCRP agencies reviewed all projects making up the Program, focusing on the scientific quality of the research, its linkages to important national and international research efforts, and its contribution to improving the understanding of global change fundamental to policy development and evaluation. As a result of this review, gaps in the Program were identified. A number of agencies redirected their program requests, and additional funds were included in the National Science Foundation budget to assure a concerted response to recommendations for an increased emphasis on social, economic, and policy sciences research; integrated assessment methodologies; terrestrial ecology; global modeling; and support for international research programs.

Of the 124 individual projects which have been part of the USGCRP, 37 show a significant increase, 70 are essentially unchanged, and 17 have been reduced to provide funds for higher priority activities, or are being scaled down after meeting their objectives. In addition, five new programs are being added to the suite of focused USGCRP activities, and 11 agency programs have been recategorized into the focused USGCRP.

Budget highlights by research area are given below. The subdivision into research areas for FY 1995 has been altered from last year to more accurately represent program thrusts; as such, direct comparisons with earlier editions of Our Changing Planet cannot be made.

a. Observing the Global System: To ensure that there are global observational systems which will provide long-term information about global change, $\$ 733 \mathrm{M}$, an increase of $\$ 128 \mathrm{M}$, is proposed for the Observations component of the USGCRP. Most of this increase is proposed to maintain the schedule for the launch of the Earth Observing System (EOS) satellites starting in 1998. These satellites will be an essential testbed for the international Global Observing System that is being planned to document changes that are occurring and to understand why these changes are occurring. New funding has also been provided to augment the existing land and ocean observation networks, and for a coordinated network of ultraviolet (UV) radiation measurement stations.

b. Managing and Archiving Information: To ensure that data are preserved and that the national and international research community has access to information about how the world is changing, \$382 $\mathrm{M}$, an increase of $\$ 105 \mathrm{M}$, is proposed for the Data and Information component of the USGCRP. Most of the increase will support the EOS Data Information System (EOSDIS), which is essential to rapidly and meaningfully making available the measurements that will be taken by EOS and related satellite systems. This increase will also support the development of a Global Change Data and Information System (GCDIS) to provide the infrastructure of the interagency data and information management program. 
c. Understanding Global Change Processes: Research on processes ranging from clouds and hydrology to atmospheric ozone and terrestrial ecology is proposed at $\$ 531 \mathrm{M}$, an increase of $\$ 74 \mathrm{M}$. This increase is primarily for supporting the intensive field and special observing phases of major international research programs. These programs, planned cooperatively by scientists and governments around the world, are directed at providing the information to understand why and how change is occurring. The budget will significantly increase funding for focused studies on terrestrial ecology, which are essential to understanding the potential impacts of global change on natural and managed ecosystems.

d. Predicting Global Change: An increase of $\$ 18 \mathrm{M}$, to a total of $\$ 67 \mathrm{M}$, is proposed to improve predictive capabilities. The USGCRP plans to move aggressively to take advantage of new capabilities for predicting the departures from the normal seasonal climates that lead to droughts and floods and to hotter than normal summers and colder than normal winters. The increase will also support new efforts to model the long-term changes in the climate and ozone that are the subject of international protocols and agreements.

e. Evaluating the Consequences of Global Change: The increase of $\$ 28.5 \mathrm{M}$ in this area is primarily the result of including recategorized research programs of the National Institutes of Health dealing with the damaging effects of ultraviolet radiation. The USGCRP will review the needs for expanded efforts in this area over the coming year, as part of the process of developing the multi-year research plan.

f. Developing Tools for Assessing Policies and Options: The USGCRP has built an increasingly impressive base of research information on global change. It will now intensify its focus on the development of capabilities for putting this information to use in the exploration and evaluation of national and international policies. This budget proposes $\$ 35 \mathrm{M}$, an increase of \$18 $\mathrm{M}$, in order to improve the integrated assessment and policy science activities within the Program.

In addition to these research program activities, the USGCRP will be increasingly involved in public outreach and education activities. Support for the education of young scientists takes place primarily through the research programs themselves. Development of educational materials is a combined effort of the research programs and agency education programs. Public outreach efforts are being developed in part by Project Earthlink, an interagency effort that will support development of global change education programs and provide systems for community access to global change information.

Go to $\underline{\text { Appendix B }}$

Return to Chapter 5

Return to Table of Contents 


\begin{tabular}{|c|c|c|c|c|c|c|}
\hline New & Library & About & Online Catalog & Ask Dr. Global Change & Site Map & Links \\
\hline
\end{tabular}

U.S. GLOBAL CHANGE
RESEARCH
INFORMATION OFFICE

Updated 1 December, 2004

\section{Global Change Acronyms and Abbreviations}

The table below is a list of global change acronyms and abbreviations gathered by GCRIO from the FY 1995 through FY 2001 editions of Our Changing Planet: The U.S. Global Change Research Program, The U.S. Global Change Data and Information System (GCDIS) Implementation Plan and other sources.

Other global change and environmental science acronym lists can be found at:

- Atmospheric Radiation Measurement Program Acronyms and Abbreviations

- Carbon Dioxide Information Analysis Center Acronyms and Abbreviations

- Earth Observing System Data and Information System (EOSDIS) Acronym and Abbreviation List

- University Corporation for Atmospheric Research (UCAR) Acronym List

- Acronym Finder

$$
\underline{A}-\underline{B}-\underline{C}-\underline{D}-\underline{E}-\underline{F}-\underline{G}-\underline{H}-\underline{I}-\underline{J}-\underline{L}-\underline{M}-\underline{N}-\underline{O}-\underline{P}-\underline{Q}-\underline{R}-\underline{S}-\underline{T}-\underline{U}-\underline{V}-\underline{W}
$$

A

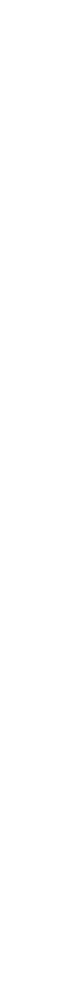
(1991-92)

ACCP Atlantic Climate Change Program

ACVE Atlantic Climate Variability Experiment

ADD The International Arctic Environment Data

AERI Atmospheric Emitted Radiance Interferometer

AIRS

AMAP Arctic Monitoring and Assessment Programme

AMSR-E Advanced Microwave Scanning

Radiometer-EOS

APEC Asia-Pacific Economic Cooperation Organization

ARCSS Arctic System Science

ARM Atmospheric Radiation Measurement Program

ASTER Advanced Spaceborne Thermal Emission and

Reflection Radiometer

ATMOS Atmospheric Trace Molecule Spectroscopy

ATS Antarctic Treaty System
AASE $\quad$ Airborne Arctic Stratospheric Expedition
ACCE Atlantic Circulation and Climate Experiment

ACRIMSAT Active Cavity Radiometer Irradiance Monitor

ADC Affiliated Data Center

AFW Air Force Weather

ALOS Advanced Land Observation Satellite

AMSU Advanced Microwave Sounding Unit

APN Asia-Pacific Network

ARGO Array for Real-time Geostrophic

Oceanography

Alaska SAR Facility

Atmospheric Laboratory for Applications and Science

ATOC Acoustic Thermometry of Ocean Climate

AVHRR Advanced Very High Resolution Radiometer
ADEOS Advanced Earth Observing Satellite

AMIP Atmospheric Model Intercomparison Project 


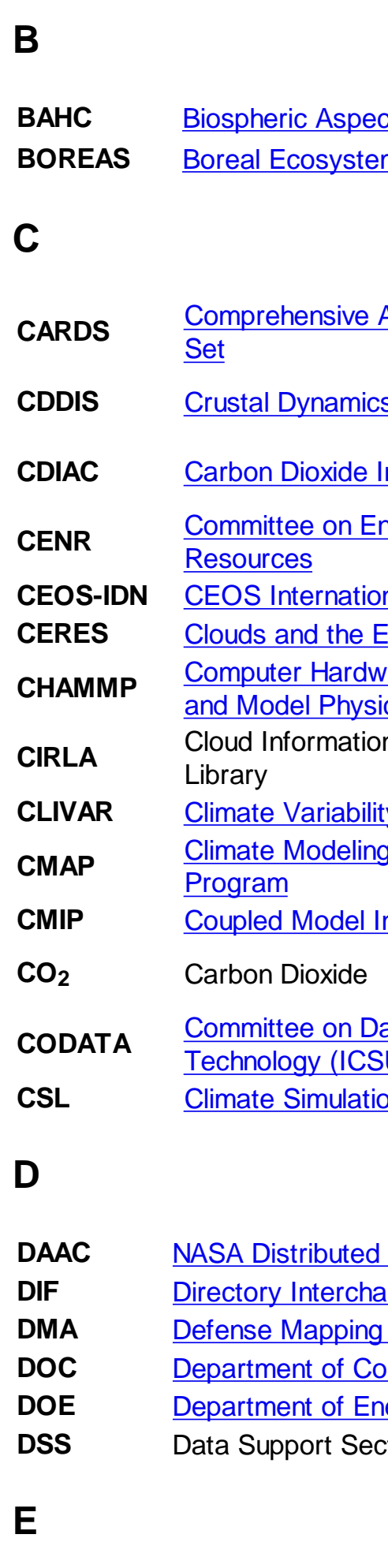

BAHC Biospheric Aspects of the Hydrological Cycle BAS British Antarctic Survey
BOREAS Boreal Ecosystem-Atmosphere Study

\begin{tabular}{|c|c|c|c|}
\hline CARDS & $\begin{array}{l}\text { Comprehensive Aerological Reference Data } \\
\text { Set }\end{array}$ & $\operatorname{ccsm}$ & Community Climate System Model \\
\hline CDDIS & Crustal Dynamics Data Information System & CDEP & $\begin{array}{l}\text { Climate Dynamics and Experimental } \\
\text { Prediction }\end{array}$ \\
\hline CDIAC & Carbon Dioxide Information Analysis Center & CEES & $\begin{array}{l}\text { Committee on Earth and Environmental } \\
\text { Sciences (obsolete) }\end{array}$ \\
\hline CENR & $\begin{array}{l}\text { Committee on Environment and Natural } \\
\text { Resources }\end{array}$ & CEOS & Committee on Earth Observation Satellites \\
\hline CEOS-IDN & CEOS International Directory Network & CEPEX & Central Equatorial Pacific Experiment \\
\hline CERES & Clouds and the Earth's Radiant Energy System & CFCs & Chlorofluorocarbons \\
\hline CHAMMP & $\begin{array}{l}\text { Computer Hardware, Advanced Mathematics } \\
\text { and Model Physics Program }\end{array}$ & CIESIN & $\frac{\text { Center for International Earth Sciences }}{\text { Information Network }}$ \\
\hline CIRLA & $\begin{array}{l}\text { Cloud Information Reference Archive and } \\
\text { Library }\end{array}$ & CLAES & Cryogenic Limb Array Etalon Spectrometer \\
\hline CLIVAR & Climate Variability and Predictability & CMA & Chinese Meteorological Admininstration \\
\hline CMAP & $\begin{array}{l}\text { Climate Modeling, Analysis and Prediction } \\
\text { Program }\end{array}$ & c & $\begin{array}{l}\text { NOAA Climate Monitoring and Diagnostics } \\
\text { Laboratory }\end{array}$ \\
\hline CMIP & Coupled Model Intercomparison Project & CNES & Centre Nationale d'Etudes Spatiales \\
\hline $\mathrm{CO}_{2}$ & Carbon Dioxide & COADS & $\begin{array}{l}\text { Comprehensive Ocean Atmosphere Data } \\
\text { Set }\end{array}$ \\
\hline CODATA & $\begin{array}{l}\text { Committee on Data for Science and } \\
\text { Technology (ICSU) }\end{array}$ & CS & $\underline{\text { Canadian Space Agency }}$ \\
\hline CSL & Climate Simulation Laboratory (at NCAR) & CzCs & Coastal Zone Color Scanner \\
\hline
\end{tabular}

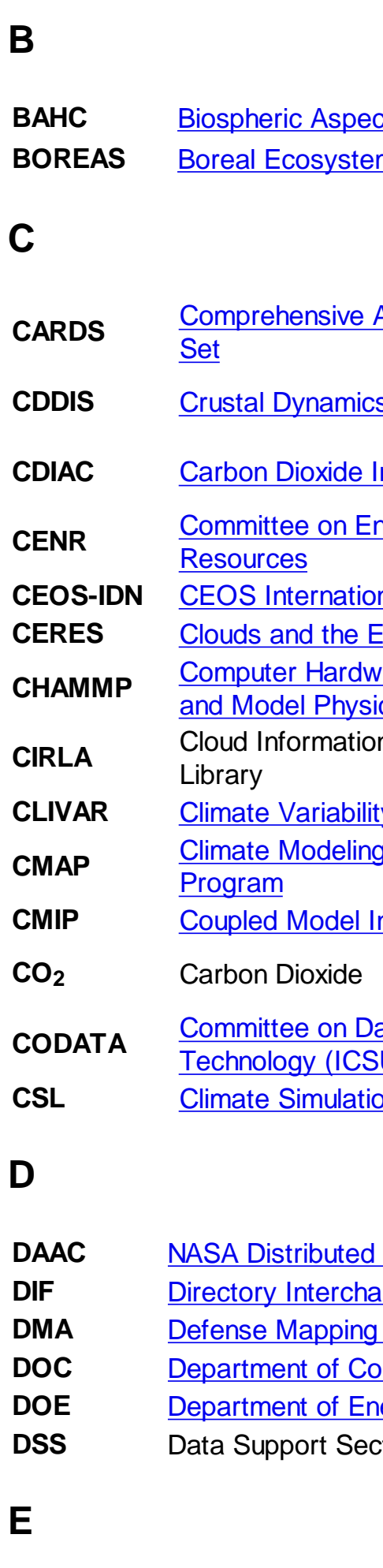

\begin{tabular}{|c|c|c|c|}
\hline DAAC & NASA Distributed Active Archive Center & DEM & Digital Elevation Model \\
\hline DIF & Directory Interchange Format & DLG & Digital Line Graph \\
\hline DMA & Defense Mapping Agency & DMSP & Defense Meteorological Satellite Program \\
\hline DOC & Department of Commerce & DOD & Department of Defense \\
\hline DOE & Department of Energy & DOI & Department of the Interior \\
\hline DSS & Data Support Section (NSF) & DTIC & Defense Technical Information Center \\
\hline
\end{tabular}

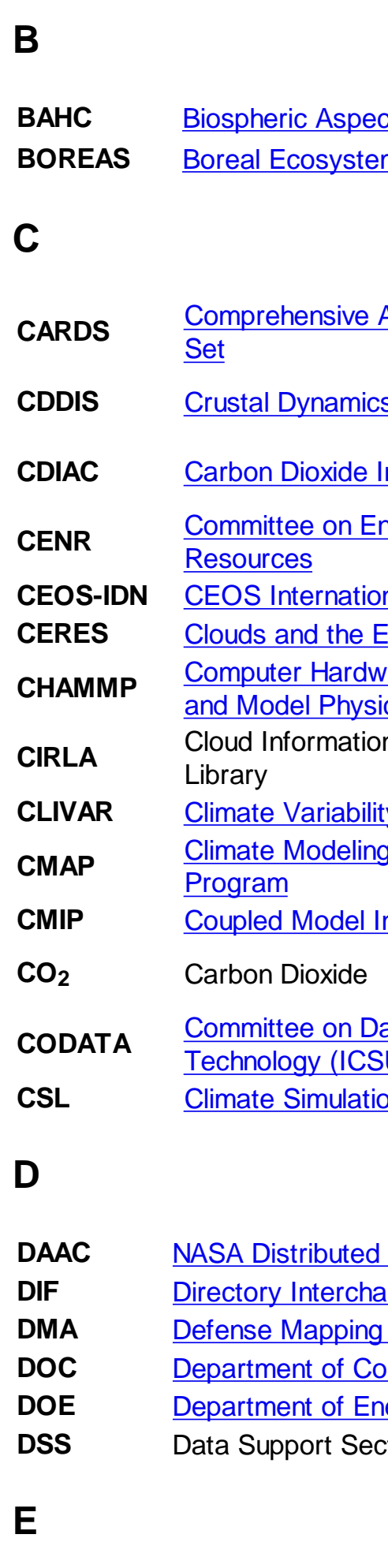

EDC EROS Data Center

\begin{tabular}{|c|c|c|c|}
\hline CPC & Experimental Climate Prediction Center & EDC & EROS Data Center \\
\hline EIA & Energy Information Administration & EMAP & $\begin{array}{l}\text { Environmental Monitoring and Assessment } \\
\text { Program (EPA) }\end{array}$ \\
\hline ENRICH & $\begin{array}{l}\text { European Network for Research in Global } \\
\text { Change }\end{array}$ & ENSO & El Niño-Southern Oscillation \\
\hline ENVISAT & Environmental Satellite & EO-ICWG & $\begin{array}{l}\text { Earth Observation International } \\
\text { Coordination Working Group }\end{array}$ \\
\hline EOS & Earth Observing System & EOSDIS & $\begin{array}{l}\text { Earth Observing System Data and } \\
\text { Information System }\end{array}$ \\
\hline A & US Environmental Protection Agency & EROC & Ecological Rates of Change \\
\hline ERB & Earth Radiation Budget & ERS & European Remote-Sensing Satellite \\
\hline
\end{tabular}




$\begin{array}{llll}\text { ESA } & \text { European Space Agency } & \text { ESnet } & \text { Energy Sciences Network } \\ \text { ESSP } & \text { Earth System Science Pathfinder Project } & \text { EUMETSAT } & \begin{array}{l}\text { European Organisation for the Exploitation } \\ \text { of Meteorological Satellites }\end{array}\end{array}$

$\mathbf{F}$

FACE $\quad$ Free Air $\mathrm{CO}_{2}$ Enrichment

FCCC Framework Convention on Climate Change

FIFE First International Satellite Land Surface Climatology Project (ISLSCP) Field Experiment

FNMOC Center

FAO Food and Agriculture Organization (United Nations)

FGDC Federal Geographic Data Committee

FIPS Federal Information Processing Standards

Fiscal Year

\section{G}

\begin{tabular}{|c|c|c|c|}
\hline GAC & Global Area Coverage & GAIM & $\begin{array}{l}\text { Global Analysis, Interpretation and } \\
\text { Modeling }\end{array}$ \\
\hline GCDIS & US Global Change Data and Information System & GCH & Global Change Climate and History \\
\hline GCIP & GEWEX Continental-Scale International Project & GCM & General Circulation Model \\
\hline GCMD & Global Change Master Directory & Gcos & Global Climate Observing System \\
\hline GCSS & GEWEX Cloud System Study & GCRIO & $\begin{array}{l}\text { US Global Change Research Information } \\
\text { Office }\end{array}$ \\
\hline GCTE & Global Change in Terrestrial Ecosystems & GDP & Gross Domestic Product \\
\hline GEMS & Global Environment Monitoring System & GEWEX & Global Energy and Water Cycle Experiment \\
\hline GFDL & Geophysical Fluid Dynamics Laboratory & GHCN & Global Historical Climatology Network \\
\hline GHRC & Global Hydrology Resource Center & GHG & Greenhouse Gas \\
\hline GILS & Government Information Locator Service & GIS & Geographic Information System \\
\hline GISS & Goddard Institute for Space Studies & GLIS & Global Land Information System (obsolete) \\
\hline GLOBE & $\begin{array}{l}\text { Global Learning and Observations to Benefit the } \\
\text { Environment }\end{array}$ & GLOBEC & $\begin{array}{l}\text { Global Marine Ecosystem Dynamics } \\
\text { Program }\end{array}$ \\
\hline GLOED & Global Emissions Database & GMS & Geostationary Meteorological Satellite \\
\hline GOALS & $\begin{array}{l}\text { Global Ocean-Atmosphere-Land System } \\
\text { Program }\end{array}$ & GODAE & Global Ocean Data Assimilation Experiment \\
\hline GOES & $\begin{array}{l}\text { Geostationary Operational Environmental } \\
\underline{\text { Satellite }}\end{array}$ & GOIN & Global Observation Information Network \\
\hline Goos & Global Ocean Observing System & GPCP & Global Precipitation Climatology Project \\
\hline GRACE & Gravity Recovery and Climate Experiment & GRID & $\begin{array}{l}\text { Global Resource Information Database } \\
\underline{(\text { UNEP) }}\end{array}$ \\
\hline GSFC & Goddard Space Flight Center & GTCP & Global Tropospheric Chemistry Program \\
\hline GTOS & Global Terrestrial Observing System & GVaP & GEWEX Water Vapor Project \\
\hline GWP & Global Warming Potential & & \\
\hline
\end{tabular}

$\begin{array}{ll}\text { HALOE } & \begin{array}{ll}\text { Halogen Occultation Experiment (satellite } \\ \text { instrument) }\end{array} \\ \text { HDP-DIS } & \begin{array}{l}\text { Human Dimensions of Global Environmental } \\ \text { Change Programme Data and Information }\end{array} \\ \text { System }\end{array}$

HCFCs Hydrochlorofluorocarbons

HFCs Hydrofluorocarbons

HSB Humidity Sounder for Brazil 
IAI

ICES

ICPSR

IDN

IGAC

IGBP-DIS

IGOS

IHP

INDOEX Indian Ocean Experiment

IOC Intergovernmental Oceanographic Commission

IPCC Intergovernmental Panel on Climate Change

ISAMS Improved Stratospheric and Mesospheric

Sounder

ISLSCP $\quad \underline{\text { International Satellite Land Surface Climatology }}$

IUGG International Union of Geodesy and Geophysics

\section{J}

JERS-1 Japan's Earth Resources Satellite

JPL Jet Propulsion Laboratory (NASA)

\section{$\mathbf{L}$}

LaRC Langley Research Center (NASA)

LITE Lidar-in-space Technology Experiment

LMER Land Margins Ecosystem Research

LUCC Land- Use and Land-Cover Change

M

(

MAB Man And the Biosphere Program

MECCA Model Evaluation Consortium for Climate

METOP Meteorological Operation (satellite)

MITI Ministry of International Trade and Industry

MMIA
Methods and Models for Integrated

Assessment (NSF Program)
IASC International Arctic Sciences Committee

ICESat Ice, Cloud, and Land Elevation Satellite

ICSU International Council of Scientific Unions

IEOS International Earth Observing System

IGBP International Geosphere-Biosphere

Programme

IGFA

International Group of Funding Agencies

International Human Dimensions of Global Environmental Change Programme

International Institute for Applied Systems

Analysis

Instituto Nacional de Pesquisas Espaciais

(Brazilian Space Agency)

International Oceanographic Data and

Information Exchange

International Research Institute for Climate Prediction

ISCCP International Satellite Cloud Climate Project

ITCZ Intertropical Convergence Zone

IWGDMGC

Interagency Working Group on Data

Management for Global Change (obsolete)

JGOFS Joint Global Ocean Flux Study
MAPSS Mapped Atmosphere-Plant-Soil System

MEDIAS MEDIterranean and Subtropical Africa

MISR Multi-angle Imaging Spectrometer

MLS Microwave Limb Sounder

MOC Meridional Overturning Circulation 


$\begin{array}{ll}\text { MODIS } & \text { Moderate Resolution Imaging Spectrometer } \\ \text { MSFC } & \text { Marshall Space Flight Center (NASA) }\end{array}$

$\mathbf{N}$

\begin{tabular}{|c|c|}
\hline NADW & North Atlantic Deep Water \\
\hline NALC & North American Landscape Characterization \\
\hline NARA & $\underline{\text { National Archive and Records Administration }}$ \\
\hline NASA & National Aeronautics and Space Administration \\
\hline NBll & National Biological Information Infrastructure \\
\hline NCAR & $\underline{\text { National Center for Atmospheric Research }}$ \\
\hline NCEP & $\underline{\text { National Centers for Environmental Prediction }}$ \\
\hline NDSC & $\begin{array}{l}\text { Network for the Detection of Stratospheric } \\
\text { Change }\end{array}$ \\
\hline NEIC & National Energy Information Center \\
\hline NESDIS & $\begin{array}{l}\text { National Environmental Satellite, Data, and } \\
\underline{\text { Information Service }}\end{array}$ \\
\hline NGDC & $\underline{\text { National Geophysical Data Center }}$ \\
\hline NII & $\underline{\text { National Information Infrastructure }}$ \\
\hline NIST & National Institute of Standards and Technology \\
\hline NOAA & $\begin{array}{l}\text { National Oceanic and Atmospheric } \\
\underline{\text { Administration }}\end{array}$ \\
\hline NODC & $\underline{\text { National Oceanographic Data Center }}$ \\
\hline NOS & National Ocean Service \\
\hline NRC & National Research Council \\
\hline NREN & $\begin{array}{l}\text { National Research and Education Network } \\
\text { (NASA) }\end{array}$ \\
\hline NSDI & National Spatial Data Infrastructure \\
\hline NSIDC & $\underline{\text { National Snow and Ice Data Center }}$ \\
\hline NSTC & National Science and Technology Council \\
\hline
\end{tabular}

$\begin{array}{ll}\text { MOPITT } & \frac{\text { Measurement of Pollutants in the }}{\text { Troposphere }} \\ \text { MSU } & \text { Microwave Sounding Unit }\end{array}$
NAL National Agricultural Library
NAO North Atlantic Oscillation
NAS National Academy of Sciences
NASDA
NBS
NCDC
NCSA
NEDRES
NESC
National Space Development Agency (Japan)
National Biological Service
National Climatic Data Center National Center for Supercomputer Applications National Environmental Data Referral Service
National Environmental Supercomputing Center

NEXRAD Next Generation Weather Radar

NIGEC

NIMA

NMFS

NOAADIR

NODIS

NPOESS

NRCSM

NSCAT

NSF

NSSDC

NTIS
National Institute for Global Environmental Change

National Imagery and Mapping Agency

National Marine Fisheries Service

NOAA Environmental Services Data

Directory

NSSDC Online Data and Information System (no longer operational)

National Polar-Orbiting Operational

Environmental Satellite System

Natural Resources Conservation Service

NASA Scatterometer

National Science Foundation

National Space Science Data Center

National Technical Information Service

$\begin{array}{ll}\text { OACES } & \text { Ocean-Atmosphere Carbon Exchange Study } \\ \text { OECD } & \frac{\text { Organisation for Economic Co-operation and }}{\text { Development }} \\ \text { OGCM } & \text { Ocean General Circulation Model } \\ \text { ONR } & \text { Office of Naval Research } \\ \text { OSTI } & \text { Office of Scientific and Technical Information } \\ \text { OTA } & \text { Office of Technology Assessment (no longer } \\ \end{array}$

P
ODP
Ozone Depletion Potential Bureau of Oceans and International OES Environmental and Scientific Affairs (US State Department)
OMB Office of Management and Budget ORNL Oak Ridge National Laboratory OSTP Office of Science and Technology Policy
OTTER Oregon Transect Ecosystem Research 


$\begin{array}{ll}\text { PDO } & \text { Pacific Decadal Oscillation } \\ \text { PFCs } & \text { Perfluorinated hydrocarbons } \\ \text { PICES } & \text { North Pacific Marine Science Organization } \\ \text { PMIP } & \text { Paleoclimatic Model Intercomparison Project } \\ \text { POEM } & \text { Polar-Orbit Earth Observation Mission } \\ \text { ppmv } & \text { Parts Per Million by Volume } \\ \text { PROBE } & \text { Pilot Radiation Observation Experiment } \\ \text { PUMS } & \text { Public Use Microdata Samples } \\ \text { Q } & \\ \text { QBO } & \text { Quasi-biennial Oscillation }\end{array}$

$\mathbf{R}$

RIC Regional Information Centre (IGBP)

RTNEPH Real Time Nephanalysis

S

SAA
SAM

SAR Synthetic Aperture Radar

SCAR Scientific Committee on Antarctic Research

SCOPE Scientific Committee On Problems of the

SCS

SDSD

SeaWiFS

SERDP

SIP

SOHO

SPARC

SPOT

SRL

SRTM

SST

START

SURFRAD

Satellite Active Archive

Stratospheric Aerosol Measurement (satellite instrument)

Environment

Soil Conservation Service

Satellite Data Services Division

Sea-viewing Wide Field-of-view Sensor

Strategic Environmental Research and

Development Program

Solar Influences Program

Solar Heliospheric Observatory

Stratospheric Processes and their Role in

Climate

Systeme pour l'Observation de la terre

Space Radar Laboratory

Shuttle Radar Topography Mission

Sea Surface Temperature

Global Change SysTem for Analysis,

Research and Training

$\mathbf{T}$
Intercomparison

PER Program for Ecosystem Research

PIBAL Pilot Balloon

PMEL Pacific Marine Environmental Laboratory

POAM Polar Ozone Aerosol Monitor

PNA Pacific North American Teleconnection

pptv Parts Per Trillion by Volume

PSC Polar Stratospheric Cloud
QuikSCAT Quick Scatterometer

RIDGE Ridge Interdisciplinary Global Experiments
SAGE Stratospheric Aerosol Gas Experiment (satellite instrument)

SAMS Surface Automated Meteorological Systems

SBUV Solar Backscatter Ultraviolet (satellite instrument)

SCAR-B Smoke, Clouds, and Radiation-Brazil

SCOR Scientific Committee On Oceanic Research

SCSMEX South China Sea Monsoon Experiment

SDTS Spatial Data Transfer Standard

SEDAC Socioeconomic Data and Applications Center

SGCR Subcommittee on Global Change Research

SIR-C Shuttle Imaging Radar-C

SPADE Stratospheric Photochemistry, Aerosols, and

Dynamics Expedition

SPAS Shuttle Pallet Satellite

SRB Surface Radiation Budget

SSBUV Shuttle Solar Backscatter Ultraviolet

SSMII Special Sensor Microwave/Imager

STA Science and Technology Agency of Japan

STD Salinity/Temperature/Depth 


\begin{tabular}{|c|c|c|c|}
\hline \multirow[b]{2}{*}{ TERRA } & \multicolumn{3}{|l|}{ system) } \\
\hline & $\begin{array}{l}\text { Terrestrial Ecosystem Regional Research } \\
\text { and Analysis Laboratory }\end{array}$ & TFODM & $\begin{array}{l}\text { Task Force on Observations and Data } \\
\text { Management (obsolete) }\end{array}$ \\
\hline TOGA & $\begin{array}{l}\text { Tropical Ocean Global Atmosphere } \\
\text { Experiment }\end{array}$ & TOGAVCOARE & $\begin{array}{l}\text { TOGA/Coupled Ocean-Atmosphere } \\
\text { Response Experiment }\end{array}$ \\
\hline TOMS & Total Ozone Mapping Spectrometer & TOPEX/Poseidon & Ocean Topography Experiment \\
\hline Tovs & Tiros Operational Vertical Sounder & TRMM & Tropical Rainfall Measuring Mission \\
\hline
\end{tabular}

$\mathbf{U}$

\begin{tabular}{|c|c|c|c|}
\hline UARS & $\underline{\text { Upper Atmosphere Research Satellite }}$ & UCAR & $\begin{array}{l}\text { University Corporation for Atmospheric } \\
\text { Research }\end{array}$ \\
\hline UN & United Nations & UNDP & United Nations Development Programme \\
\hline UNEP & United Nations Environment Programme & UNESCO & $\begin{array}{l}\text { United Nations Educational, Scientific and } \\
\underline{\text { Cultural Organization }}\end{array}$ \\
\hline UNFCCC & $\begin{array}{l}\text { United Nations Framework Convention on } \\
\text { Climate Change }\end{array}$ & UNIDATA & University Data System \\
\hline USDA & United States Department of Agriculture & USGCRP & $\begin{array}{l}\text { United States Global Change Change } \\
\text { Research Program }\end{array}$ \\
\hline USGS & United States Geological Survey & USMARC & United States Machine Readable Cataloging \\
\hline UV & Ultraviolet radiation (including UV-A and UV-B) & UV-B & Ultraviolet-B \\
\hline
\end{tabular}

V

vamos Variability of the American Monsoon System

VENTS A NOAA Program on Mid-Ocean Ridges

\section{W}

WCP World Climate Programme

WCRP World Climate Research Programme

WDC World Data Center

WEAVE Vegetative, and Earth Interactions (NSF

WEBB $\quad$ Water, Energy, and Biogeochemical Budget

WMO World Meteorological Organization

WHO World Health Organization

WOCE World Ocean Circulation Experiment

U.S. Global Change Research Information Office, Suite 250, 1717 Pennsylvania Ave, NW, Washington, DC 20006. Tel: +1 202223 6262. Fax: +1 202223 3065. Email: information@gcrio.org. Web: www.gcrio.org. Webmaster: webmaster@gcrio.org.

U.S. Global Change Research Information Office www.gcrio.org 


\section{APPENDIX D:}

\section{Subcommittee on Global Change Research (SGCR) of the Committee on Environment and Natural Resources Research (CENR)}

Robert W. Corell

Charles F. Kennel

Susan F. Tierney

J. Michael Hall

Aristides A. Patrinos

Nancy G. Maynard

Gary R. Evans

Robert Watson

Thomas J. Baerwald

Jack D. Fellows

Mary M. Gant

Ted A. Maxwell

Norris A. Nielsen

Kevin O'Connell

Stephen E. Ragone

Courtney Riordan

Fred E. Saalfeld

William L. Sullivan, Jr.
Chair

National Science Foundation

Vice-Chair, Science

National Aeronautics and Space Administration

Vice-Chair, Policy

Department of Energy

Chair, Integrative Modeling and Prediction Working Group

Department of Commerce/National Oceanic and Atmospheric Administration

Chair, Process Research Working Group

Department of Energy

Chair, Observations, and Data and Information Management Working Group National Aeronautics and Space Administration

Co-Chair, Assessment Working Group Chair, Education Task Group Department of Agriculture

Co-Chair, Assessment Working Group

office of Science and Technology Policy

National Science Foundation

Office of Management and Budget

Department of Health and Human Services/National Institute of $\mathrm{E}$ Smithsonian Institution

Tennessee Valley Authority

Intelligence Community

Department of the Interior

Environmental Protection Agency

Department of Defense

Department of State

\section{White House Liasons}

Rosina Bierbaum

Sally Kane

Sara Horrigan

\section{Task Groups}

Office of Science and Technology Policy

Council of Economic Advisers

Office of Management and Budget 
Daphne D. Gemmill Director, Project Earthlink

Department of Commerce/National Oceanic and Atmospheric Administration

\section{Coordination Office of the U.S. Global Change Research Program}

$\begin{array}{ll}\text { Michael C. MacCracken } & \text { Director } \\ \text { Sylvia A. Edgerton } & \text { Deputy Director }\end{array}$

Richard H. Moss Warren T. Spaeth Wanda R. Ferrell Rick Kelly Sean L. Downing Clary B. Washington

Linda V. Moodie

Susan C. Henson

Gerald S. Barton

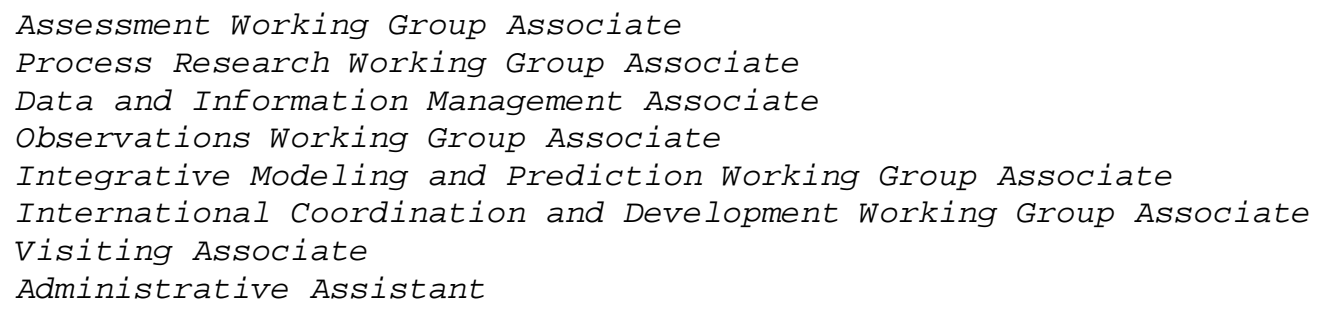

Director, Global Change Research Information office

Go to Appendix E

Return to the Table of Contents 


\section{APPENDIX E:}

\section{Management and Implementation of the USGCRP}

\section{Program History and Organization}

The U.S. Global Change Research Program was established in 1989 to combine and coordinate the research and policy development interests of 18 departments and agencies of the U. S. Government and Executive Offices of the President. The USGCRP is organized under the auspices of the Subcommittee on Global Change Research (SGCR), which is one of the seven environmental issue subcommittees established by the Committee on the Environment and Natural Resources Research (CENR)[which has replaced the Committee on Earth and Environmental Sciences (CEES)]. In turn, the CENR is one of the nine committees organized under the National Science and Technology Council (NSTC), which on November 23, 1993 assumed the responsibilities of the Federal Coordinating Council on Science, Engineering and Technology, the National Space Council, and the National Critical Materials Council.

The Subcommittee on Global Change Research includes representatives of the Departments of Agriculture, Commerce (the National Oceanic and Atmospheric Administration), Defense, Energy, Health and Human Services (represented by the National Institute for Environmental Health Sciences), Interior, and State as well as the Environmental Protection Agency, the National Aeronautics and Space Administration, the National Science Foundation, the Smithsonian Institution, the Tennessee Valley Authority, the Agency for International Development, the Intelligence Community, the Office of Science and Technology Policy, Council of Economic Advisors, Office of Environmental Policy, and the Office of Management and Budget.

To implement the activities described in the USGCRP research framework, the SGCR has established Working Groups that bring together representatives of the participating agencies for regular consideration of program coordination, review of program plans, and development of plans for new projects and activities. The Chairs of these groups, along with the Chair and Vice-Chairs of the Subcommittee, for the Executive Committee of the USGCRP. To ensure effective Program integration across these activities, the SGCR established the Office of the USGCRP in July 1993. This office, which is staffed by the participating agencies and departments, is responsible for drafting of the USGCRP annual report and the triennial ten-year research plan, as well as facilitating the year-to- year planning and day-to-day coordination and communication needs of the Program.

The planning, coordination, and execution of USGCRP research activities are carried out in close association with and in support of the science priorities of the international research community, particularly those put forth by the Intergovernmental Panel on Climate Change (IPCC), the World Climate Research Program (WCRP), the Human Dimensions Programme for Global Change (HDP), and the International GeosphereBiosphere Programme (IGBP). These efforts underpin the participation of the United States in and contribution to the international assessments related to aspects of global change.

The USGCRP maintains an active interaction with the National Academy of Sciences through its Board on Global Change and other committees and panels of the National Research Council, which also provide an interface with many of the international scientific research programs.

\section{Program Evaluation}

The overall USGCRP is periodically evaluated for scientific merit and continued relevance to the policy 
process, both domestic and international. This independent review process variously involves academic, state, industry, and other groups conducting global change research, such as the National Academy of Sciences. This review function will be particularly active in 1994 as the new USGCRP multi- year plan is developed.

Proposed and existing agency programs within the USGCRP are evaluated based on: (i) their relevance and contribution to the overall USGCRP goal and objectives, including the needs of decision makers; (ii) scientific merit as documented by peer review; (iii) readiness for implementation and likelihood of early results; (iv) potential for and/or progress toward meeting program milestones; (v) agency approval for inclusion in the USGCRP; and (vi) conformance to data and information management policies. The framework and evaluation criteria are an essential part of the program and budget development strategy of the USGCRP. They provide the structure through which the USGCRP evaluates and develops: (1) essential, high priority national and international components of the USGCRP in each fiscal year; and (2) the recommended budgets to support those critical components.

In addition to USGCRP review of the overall set of agency research programs, each agency is responsible for the review of individual projects within its programs. These reviews are almost exclusively based on an external peer review process, which is deemed an important means of assuring continued program quality.

In the past year, the SGCR conducted a review of all USGCRP programs to determine their priority to meeting the goals and objectives of the USGCRP, using criteria of scientific merit, relationship to stakeholders, and policy relevance. The SGCR also evaluated the programs in relation to the USGCRP research framework. The evaluation and review resulted in the identification of significant gaps in the Program. As a result, the proposed FY 1995 USGCRP budget includes an augmented request to address the priorities identified in the interagency initiative efforts.

Coordination Office of the U.S. Global Change Research Program

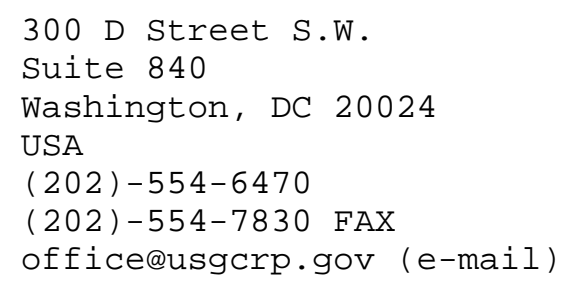

Return to Table of Contents 